\title{
IDENTIFICATION OF GENES
}

\section{AND REGULATORS THAT ARE SHARED \\ ACROSS T CELL ASSOCIATED DISEASES}

\author{
Danuta R. Gawel
}

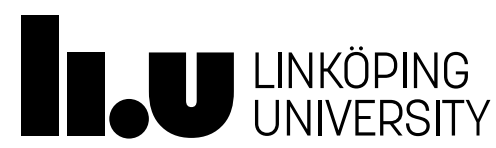

The Center for Personalised Medicine

Department of Clinical and Experimental Medicine Linköping University, Sweden

Linköping 2018 
(C)Danuta R. Gawel, 2018

Design: Danuta R. Gawel

Published articles has been reprinted with the permission of the copyright holder.

Printed in Sweden by LiU-Tryck, Linköping, Sweden, 2018

ISBN: 978-91-7685-320-7

ISSN: 0345-0082 
Any knowledge that doesn't lead to new questions quickly dies out: it fails to maintain the temperature required for sustaining life.

—Wistawa Szymborska- 


\section{SUPERVISOR}

Professor Mikael Benson

The Center for Personalised Medicine

Department of Clinical and Experimental Medicine

Linköping University, Sweden

\section{Co-SUPERVISORS}

Docent Mika Gustafsson

Department of Physics, Chemistry and Biology

Linköping University, Sweden

PhD Colm Nestor

Department of Clinical and Experimental Medicine

Linköping University, Sweden

\section{OPPONENT}

Docent Erik Larsson Lekholm

Department of Medical Biochemistry and Cell biology at Institute of Biomedicine University of Gothenburg, Sweden 


\section{Table of Contents}

0 Acknowledgements

1 Identifiering av gener och regulatorer som delas av flera olika $\mathbf{T}$ cells associerade sjukdomar

2 Abstract

3 List of original papers $\quad 13$

4 Abbreviations $\quad 15$

$\begin{array}{llr}5 & \text { Introduction } & 19\end{array}$

6 Materials and Methods $\quad 31$

6.1 Study subjects . . . . . . . . . . . . . . . . 31

6.2 Ethics statement . . . . . . . . . . . . . . . 32

6.3 Definition of low and high responders to treatment . . . . . 33

6.4 GWAS data accession . . . . . . . . . . . . . . . . . . . . . . . 33

6.5 Enrichment analyses ................... 34

6.6 Public T-cell disease data . . . . . . . . . . . . . . . . 34

6.7 Gene expression microarray data processing . . . . . . . . 35

6.8 Analyses of sets of genes . . . . . . . . . . . . . . 36

6.9 Disease-associated network modules . . . . . . . . . . 36

6.10 Shared disease module validation in several human interactome databases . . . . . . . . . . . . . . . . . 37

6.11 Classifications . . . . . . . . . . . . . . 37

6.12 Th1/Th2 regulatory region analysis . . . . . . . . . . . . . . . 38

6.13 Construction of the Th1/Th2 GRN . . . . . . . . . . . . . 38

6.14 TF-target relationship correlation analyses . . . . . . . . . 39

6.15 ChIP-Seq analyses . . . . . . . . . . . . . . . . . 40

6.16 Gene Regulatory Network and TFBS comparison using ChIPSeq peak counts . . . . . . . . . . . . . . 40

6.17 Splice associated SNPs . . . . . . . . . . . . . . . . . . . . . . . . . . . . . 40

6.18 Expression quantitative trait loci . . . . . . . . . . . . 41

6.19 siRNA mediated gene knock down . . . . . . . . . . . . . . 41

6.20 Sublingual immunotherapy $($ SLIT) . . . . . . . . . . . . . . . . . . 41

6.21 Quantitative PCR (qPCR) . . . . . . . . . . . 41

6.22 MS gene expression in relapse and remission . . . . . . . . . . 42

6.23 GWAS analysis of multiple sclerosis . . . . . . . . . . . 42

6.24 Construction of miR-mRNA regulatory network and module identification . . . . . . . . . . . . . . . . 42 
7 Results and Discussion $\mathbf{4 5}$

7.1 Project I: Identification of shared disease genes . . . . . . . . 45

7.2 Project II: Identification of the upstream regulators . . . . . . 53

7.3 Project III: microRNAs in T helper cell differentiation and in $\mathrm{T}$ cell related diseases . . . . . . . . . . . . . . 65

8 Concluding Remarks $\quad 73$

$\begin{array}{lll}9 & \text { Paper I } & 97\end{array}$

10 Paper II 111

11 Manuscript $\quad 123$ 


\section{Acknowledgements}

"We are not lost. We're locationally challenged."

- John M. Ford -

In science there is no easy path that would lead straight to answers. In research, as in life, it is vital to be surrounded by great people sharing one goal. Here I would like to express my gratitude to everyone that joined me on my PhD journey.

To Mikael Benson, my supervisor, exceptional leader, who has welcomed me as $\mathrm{PhD}$ student in his group. His guidance and support broaden my horizons not only regarding scientific aspects. Thank you for the encouraging words that I needed so much, especially when I was becoming lost and confused (but always 'at the higher level').

To Mika Gustafsson, my co-supervisor, outstanding teacher, to whom I owe incredible development in the key field for me: bioinformatics. Thank you for recurring remainders of a big picture when I was getting too focused on details.

To Colm Nestor, my co-supervisor, for great assistance and always constructive, very precise and scientific critique, which never put me down but instead encouraged to search answers in a better way - which in my opinion is a very unique skill.

To my present and past co-workers for hours, and hours of great inspiring scientific discussions and lightening chats over the coffee. Special thanks to Huan Zhang, Jordi Serra Musach, Antonio Lentini, Cathrine Lagerwall, Sandra Lilja, Lina Mattson, and Robert Liljenström.

To Mattias Köpsén and Zainab Chaudry for putting up with me as your co-supervisor. It has been a great pleasure to work with you. You have been my teachers too.

To everyone at Cell Biology floor 13 for worm welcome, all the coffee and lunch breaks, and other activities, especially to Annelie Lindström, Björn Ingelsson, Birgitta Holmlund, and Ivana Tichá.

Last but not least I would like to thank my great family for never-ending, unquestionable support in every step I take. To my dearest husband thanks to whom even the darkest night isn't scary. To my beloved son who with a 
single smile brings things back to the right perspective. To my parents and sisters who always encourage me and stand by my side 'no matter what'.

Here I would like to also thank one more person that have inspired me to start this journey, great teacher - Krzysztof Fujarewicz.

Thank you! 


\section{Identifiering av gener och regulatorer som delas av flera olika $T$ cells associerade sjukdomar}

Genomvida associations studier (GVAS) gör det möjligt att studera miljontals små variationer i människans gener. Sådana studier har utförts på hundratals olika sjukdomar och miljontals patienter. Ett viktigt fynd är att samma gener kan vara associerade med olika sjukdomar, s.k. delade gener. Målen för min avhandling var att identifiera a) delade gener, b) vilka gener som hade uppströms, reglerande funktioner, samt c) hur samma gener kan vara associerade med olika sjukdomar.

Jag studerade en viss sorts vit blodkropp, s.k. CD4+ T celler, eftersom analys av alla GVAS gener visade att en signalväg som är uttryckt i denna celltyp var statistiskt mest signifikant. Jag studerade därför genaktiviteten, i form av mRNA uttryck, i denna celltyp vid flera olika sjukdomar. Detta gjordes med mikromatristeknik så att mRNA nivåerna för flertalet av människans gener kunde mätas. Genom att jämföra med mRNA nivåerna hos friska kunde tusentals sjukdomsassocierade gener och deras mRNA uttryck identifieras (s.k. transkript). För att få en överblick över dessa mappade jag, med datorns hjälp, transkripten på en nätverkskarta över mänskliga gener och deras interaktioner. Jag fann att många delade transkript fanns på samma ställe på kartan och därför var mycket hopkopplade. Bioinformatiska analyser visade att dessa transkript ingick i livsviktiga signalvägar som reglerade inflammation, ämnesomsättning och celltillväxt. Detta ledde till hypotesen att sjukdomsassocierade förändringar i någon av de delade transkripten skulle skulle kunna spridas till mer än en signalväg och därigenom orsaka en eller flera sjukdomar. Hypotesen stöddes av att de gener som kodade för de delade transkripten var kraftigt berikade för genetiska varianter som identifierats av GVAS. Den andra frågan i min avhandling, vilka gener som hade reglerande funktioner, studerade jag genom att konstruera en nätverksmodell som över tid beskrev hur transkript aktiverades i CD4+ T celler. Jag fann då att tre s.k. transkriptions faktorer hade en övergripande roll vid många sjukdomar, och validerade detta genom studier av symptomfria stadier hos patienter med pollensnuva och multipel skleros. I en tredje studie analyserade jag en an- 
nan sorts reglermolekyler, s.k. microRNA, men fann att de huvudsakligen var inblandade i senare stadier av olika sjukdomar. Avseende den tredje frågan i avhandlingen, hur samma gener kan vara inblandade i olika sjukdomar fann jag två förklaringar: 1) olika nivåer av samma transkript, samt 2) olika funktion av samma gen p.g.a. genetiska varianter.

Sammanfattningsvis fann jag att delade gener kan vara viktiga för uppkomsten av flera olika sjukdomar, och att detta kan bero på olika mRNA uttryck eller funktion hos samma gen. 


\section{Abstract}

Genome-wide association studies (GWASs) of hundreds of diseases and millions of patients have led to the identification of genes that are associated with more than one disease. The aims of this $\mathrm{PhD}$ thesis were to a) identify a group of genes important in multiple diseases (shared disease genes), b) identify shared up-stream disease regulators, and c) determine how the same genes can be involved in the pathogenesis of different diseases. These aims have been tested on CD4+ T cells because they express the $\mathrm{T}$ helper cell differentiation pathway, which was the most enriched pathway in analyses of all disease associated genes identified with GWASs.

Combining information about known gene-gene interactions from the protein-protein interaction (PPI) network with gene expression changes in multiple $\mathrm{T}$ cell associated diseases led to the identification of a group of highly interconnected genes that were miss-expressed in many of those diseases - hereafter called 'shared disease genes'. Those genes were further enriched for inflammatory, metabolic and proliferative pathways, genetic variants identified by all GWASs, as well as mutations in cancer studies and known diagnostic and therapeutic targets. Taken together, these findings supported the relevance of the shared disease genes.

Identification of the shared upstream disease regulators was addressed in the second project of this $\mathrm{PhD}$ thesis. The underlying hypothesis assumed that the determination of the shared upstream disease regulators is possible through a network model showing in which order genes activate each other. For that reason a transcription factor-gene regulatory network (TF-GRN) was created. The TF-GRN was based on the time-series gene expression profiling of the $\mathrm{T}$ helper cell type 1 (Th1), and T helper cell type 2 (Th2) differentiation from Naïve T-cells. Transcription factors (TFs) whose expression changed early during polarization and had many downstream predicted targets (hubs) that were enriched for disease associated single nucleotide polymorphisms (SNPs) were prioritised as the putative early disease regulators. These analyses identified three transcription factors: GATA3, $M A F$ and $M Y B$. Their predicted targets were validated by ChIP-Seq and siRNA mediated knockdown in primary human T-cells. $\mathrm{CD} 4+\mathrm{T}$ cells isolated from seasonal allergic rhinitis (SAR) and multiple 
sclerosis (MS) patients in their non-symptomatic stages were analysed in order to demonstrate predictive potential of those three TFs. We found that those three TFs were differentially expressed in symptom-free stages of the two diseases, while their TF-GRN-predicted targets were differentially expressed during symptomatic disease stages. Moreover, using RNA-Seq data we identified a disease associated SNP that correlated with differential splicing of GATA3.

A limitation of the above study is that it concentrated on TFs as main regulators in cells, excluding other potential regulators such as microRNAs. To this end, a microRNA-gene regulatory network (mGRN) of human CD4+ T cell differentiation was constructed. Within this network, we defined regulatory clusters (groups of microRNAs that are regulating groups of mRNAs). One regulatory cluster was differentially expressed in all of the tested diseases, and was highly enriched for GWAS SNPs. Although the microRNA processing machinery was dynamically upregulated during early T-cell activation, the majority of microRNA modules showed specialisation in later time-points.

In summary this $\mathrm{PhD}$ thesis shows the relevance of shared genes and up-stream disease regulators. Putative mechanisms of why shared genes can be involved in pathogenesis of different diseases have also been demonstrated: a) differential gene expression in different diseases; b) alternative transcription factor splicing variants may affect different downstream gene target group; and c) SNPs might cause alternative splicing. 


\section{List of original papers}

This thesis is based on the following original papers:

\section{PROJECT I}

Gustafsson, M.; Edström, M.; Gawel, D.; Nestor, C. E.; Wang, H.; Zhang, H.; Barrenäs, F.; Tojo, J.; Kockum, I.; Olsson, T.; Serra-Musach, J.; Bonifaci, N.; Pujana, M. A.; Ernerudh, J.; Benson, M., Integrated genomic and prospective clinical studies show the importance of modular pleiotropy for disease susceptibility, diagnosis and treatment. Genome Med 2014, 6(2), 17.

\section{PROJECT II}

Gustafsson, M. ${ }^{\dagger}$; Gawel, D. R ${ }^{\dagger}$.; Alfredsson, L.; Baranzini, S.; Björkander, J.; Blomgran, R.; Hellberg, S.; Eklund, D.; Ernerudh, J.; Kockum, I.; Konstantinell, A.; Lahesmaa, R.; Lentini, A.; Liljenström, H. R.; Mattson, L.; Matussek, A.; Mellergård, J.; Mendez, M.; Olsson, T.; Pujana, M. A.; Rasool, O.; Serra-Musach, J.; Stenmarker, M.; Tripathi, S.; Viitala, M.; Wang, H.; Zhang, H.; Nestor, C. E. ${ }^{\dagger}$; Benson, M. ${ }^{\dagger}$, A validated gene regulatory network and GWAS identifies early regulators of T cell-associated diseases. Sci Transl Med 2015, 7(313), 313ra178.

\section{PROJECT III}

Gawel, D. R. ${ }^{\dagger}$; Lentini, A. ${ }^{\dagger}$; Lagerwall, C.; Jordi, S.-M.; Konstantinell, A.; Hui, W.; Chaudry, Z.; Zhang, H.; Rundquist, O.; Gustafsson, M.; Benson, M. ${ }^{\dagger}$; Nestor, C. E. ${ }^{\dagger}$, Time-series profiling of human CD4+T-cells identifies a microRNA-mRNA network disrupted in diseases of the human immune system. Manuscript

$\dagger$ These authors contributed equally to this work and should be regarded as shared first or last authors, respectively. 


\section{Abbreviations}

In the alphabetical order:

AGO2

ALL

AML

ATL

AUC

CEP290

CFTR

ChIP-Seq

CLL

DE

DGCR 8

DHS

DICER

$D M D$

DROSHA

eQTL

ex-miRs

FE

FET

FN1

GATA3

GCs

GN

GO

GRN

GWAS

HES

HIV

Argonaute 2, RISC catalytic component

Acute lymphoblastic leukemia

Acute myeloid leukaemia

Adult T cell leukaemia/lymphoma

Area under ROC curve

Centrosomal protein 290

Cystic fibrosis transmembrane conductance

Chromatin immunoprecipitation-sequencing

Chronic lymphoid leukaemia

Differentially expressed

DGCR8, microprocessor complex subunit

DNase I hypersensitive sites

Dicer 1, ribonuclease III

Dystrophin

Drosha ribonuclease III

Quantitative trait loci

Extracellular miRs

Fold enrichment

Fisher exact test

Fibronectin 1

GATA binding protein 3

Glucocorticoids

Gene network

Gene ontology

Gene regulatory network

Genome wide association study

Hypereosinophillic syndrome

Human immunodeficiency virus infection

HRs and LRs High- and low-responders respectively

IKZF 1 


\begin{tabular}{|c|c|}
\hline IL23R & Interleukin 23 receptor \\
\hline IPA & Ingenuity pathway analysis \\
\hline KEGG & Kyoto encyclopedia of genes and genomes \\
\hline LASSO & Least absolute shrinkage and selection operator \\
\hline $\mathrm{LCC}$ & Largest connected component \\
\hline $\mathrm{LD}$ & Linkage disequilibrium \\
\hline$L E F 1$ & Lymphoid enhancer binding factor 1 \\
\hline $\operatorname{lncRNAs}$ & Long non-coding RNAs \\
\hline$M A F$ & MAF bZIP transcription factor \\
\hline mGRN & MicroRNA-Gene Regulatory Network \\
\hline $\operatorname{miR}$ & MicroRNA \\
\hline MS & Multiple sclerosis \\
\hline$M Y B$ & MYB proto-oncogene, transcription factor \\
\hline $\mathrm{NOTCH}_{4}$ & Notch 4 \\
\hline NT & Naïve T cell \\
\hline NZB & Humanized monoclonal antibody which binds to $\alpha 4 \beta 1$ - integrin \\
\hline OMIM & Online mendelian inheritance in man \\
\hline OR & Odds ratio \\
\hline$P A H$ & Phenylalanine hydroxylase \\
\hline pAID & Paediatric-age-of-onset autoimmune diseases \\
\hline PBMCs & Peripheral blood mononuclear cells \\
\hline PCC & Pearson's correlation coefficient \\
\hline PPI & Protein- protein interactions \\
\hline PTPN22 & Protein tyrosine phosphatase, non-receptor type 22 \\
\hline RA & Rheumatoid arthritis \\
\hline RISC & RNA-induced silencing complex \\
\hline rSNP & Regulatory SNP \\
\hline SAR & Seasonal allergic rhinitis \\
\hline $\mathrm{SeS}$ & Sézary syndrome \\
\hline siRNA & Small interfering RNA \\
\hline SLE & Systemic lupus erythematosus \\
\hline SLIT & Sublingual immunotherapy \\
\hline$S M N 2$ & Survival of motor neuron 2 , centromeric \\
\hline SNP & Single nucleotide polymorphism \\
\hline SRS & Splice regulatory sites \\
\hline$T A R B P 2$ & TARBP2, RISC loading complex RNA binding subunit \\
\hline TERT & Telomerase reverse transcriptase \\
\hline
\end{tabular}




$\begin{array}{ll}\text { TF } & \text { Transcription factor } \\ \text { TFBS } & \text { Transcription factor binding sites predictions } \\ \text { TF-GRN } & \text { TF-Gene regulatory network } \\ \text { Th1 } & \text { T helper cell type } 1 \\ \text { Th2 } & \text { T helper cell type } 2 \\ \text { Th17 } & \text { T helper cell type } 17 \\ \text { Treg } & \text { T regulatory cell (Treg) } \\ \text { T1D } & \text { Type } 1 \text { diabetes } \\ \text { XPO5 } & \text { Exportin } 5 \\ \text { 3'(5')UTR } & \text { 3' (5') untranslated region }\end{array}$




\section{Introduction}

Molecular cell biology is a very complex field, with many unknowns and uncertainties. For over a century many researches has been following the rule of 'divide and conquer' in order to gain insights into underlying mechanisms of biological processes. Following that rule much of twentieth-century has been an attempt to reduce biological phenotypes to individual cellular components like genes and proteins $[1,2,3]$. Following the assumption that a trait spread over families is synonymous with inheritance of an error in a single molecule, many monogenic disorders were found, including phenylketonuria $(P A H)$ [4], cystic fibrosis (CFTR) [4], and many others [4,5]. Despite the huge success of reductionism in identification of monogenic genetic disorders, it has been later recognised that in general the link between genotype and phenotype is far too complex to be explained by a change in single gene [3]. This effect is especially noticeable in complex diseases which are an effect of multiple genetic factors, together with environmental and lifestyle components $[4,6]$. This gave rise to large-scale association studies which were believed to have a greater power in identification of disease genes even if those would have more modest effects [6]. Genome Wide Association Studies (GWASs) aim to identify genetic variants associated with a given trait in different individuals. Typically, GWASs focus on associations between single-nucleotide polymorphisms (SNPs) and human diseases but also other clinical conditions, like height or longevity. This genome-wide approach in human genetics gives an opportunity to identify genetic factors that contribute to human diseases.

Remarkably, among hundreds of studied diseases and millions of patients, GWASs identified many SNPs to be associated with more than one disease or trait. It has been reported that $4.6 \%$ of GWAS SNPs show pleiotropic effects [7]. In fact, more than half of the autoimmune GWAS SNPs are associated with at least two distinct autoimmune diseases $[8,9]$. Furthermore, linking GWAS variants to genes has given an insight into genes associated with more than one disease. A widely known example is PTPN22, which is associated with type 1 diabetes, rheumatoid arthritis and Crohn's disease [10]. In ten paediatric-age-of-onset autoimmune diseases (pAIDs) [11] a genome wide study identified 27 loci significantly associated 
with at least one pAID. Interestingly, they found 8 risk alleles shared by combined pAIDs, but that were also associated with protection against one of the pAIDs. Those findings led to the main question in this thesis: How can the same genes contribute to pathogenesis of different diseases?

Previous work has suggested some answers to this question. In a systematic analysis of 14 tumour types in [12] the authors searched for somatic mutations in regulatory regions that affect mRNA expression. One exceptional example was mutations in the promoter region of TERT, which were strongly associated with expression increase. However, those mutations and expression changes varied greatly between different tumours. This example shows how different changes of the same gene or its regulation can be associated with different disease manifestation - here expression change is putatively caused by a somatic mutation and/or copy number alterations and/or by somatic structural variants as shown in another study of 600 tumour and 18 cancer types [13]. However cancer is a very specific group of diseases, and therefore this example shows how one gene's expression might vary in different cancers and what might cause those differences, but it doesn't answer how the same gene might contribute to pathogenesis of different diseases.

In another study meta-analysis of expression profiling data from several different cells and tissues from inflammatory, malignant and metabolic diseases showed that transcripts that were shared by more than one disease tended to co-localise when mapped on the human protein-protein interaction (PPI) network [14]. By inference, they were more interconnected than expected by chance. This is at least partially consistent with previous research showing that genes associated with phenotypically similar diseases tend to be interconnected and also functionally related [15]. However, the diseases in the expression profiling meta-analysis were highly diverse. How can the same, highly interconnected and presumably functionally related transcripts be associated with different diseases? To answer this question, the transcripts were analysed for pathway enrichment. In other words, did the transcripts belong to any pathways? Indeed, the transcripts were highly enriched for inflammatory, metabolic and proliferative pathways. This suggested a hypothetical explanation for why the same genes could be associated with more than one disease: Those pathways have key roles, and because of their interconnectivity, malfunction in one could lead to malfunction in the others and thereby increase the risk for one or more dis- 
eases. This hypothetical explanation was supported by meta-analysis of independent GWASs data of 145 other complex diseases: There was highly significant enrichment of genetic variants identified by those GWASs [14].

Later, it was shown that interplay between three endophenotypes (inflammation, fibrosis and thrombosis) and local organ-based environment may lead to disease-specific gene expression [16]. They identified that disease-genes associated with $52 \%$ of 299 studied diseases significantly overlapped with at least one of the 3 endophenotypes, whereas over $22 \%$ were enriched in all three endophenotypes. Taken together, these findings support that inflammation, fibrosis and thrombosis are common to many complex diseases, and that differential expression in different organ systems can explain why the same genes can contribute to pathogenesis of different diseases.

These studies also highlight an important concept underlying this thesis. The background to this concept is that in many studies pleiotropic SNPs/genes are analysed separately as independent incidents. This could be a limitation since many relationships between genotype and phenotype are difficult to explain by single molecules $[3,17]$. In fact, many cellular processes are a result of multiple coordinated, often very complex, mechanisms. Therefore scaling-up from individual molecules to groups of functionally and/or psychically coordinated molecules is a potentially advantageous concept [1].

One way to identify such coordinated molecules is to identify gene modules. This concept requires introducing of a few definitions. First of all, a gene network, which can be seen as a graphical representation of gene to gene interactions (Fig.1). Nodes (circles) represent genes or proteins, and lines (edges) represent interactions. In such a representation highly connected genes (nodes connected with many edges) would form a module (Fig.1).

Here again both nodes and the edges (genes and gene interactions) have to be contemplated in the context of specific cell type and tissue $[18,19,20]$, as they will differ in different cells depending on the cell function. In line with the 'guilty-by-association' or 'local' hypothesis, if a particular gene is involved in a process or disease, its direct interactors (neighbours) are also suspected to have some role in the same process [17]. Also in line with that hypothesis, the cellular components that are associated with a specific disease phenotype tend to cluster together in the same network neighbour- 


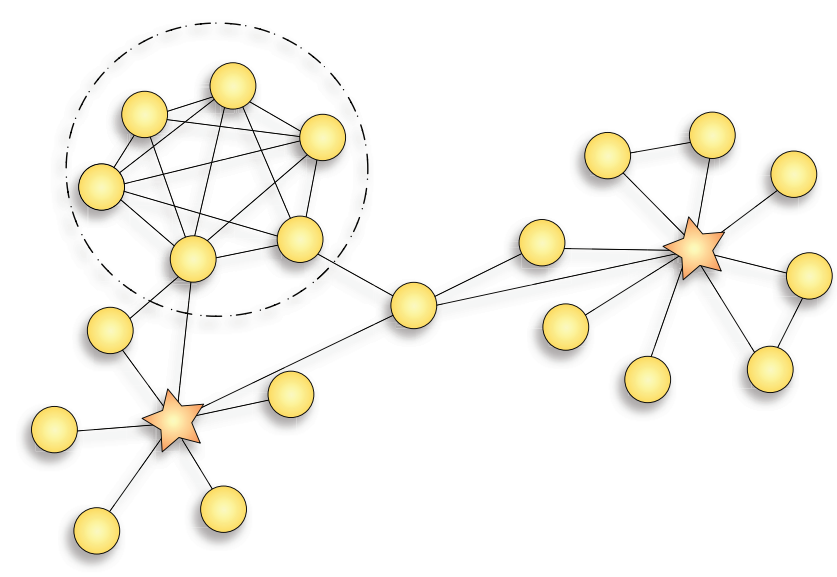

Figure 1: Gene network (GN) - each node (disks and stars) represents a gene or protein, whereas each line represents interaction between genes/proteins. Black dashed circle marks a gene/protein module - a highly connected set of nodes. Stars represent nodes with many neighbours - hubs.

hood $[14,17,21,22]$. Consequently, a group of tightly connected genes that contribute to a disease phenotype hereafter will be referred to as 'disease module'. Disease modules tend to at least partially overlap with functional modules (modules of genes coordinated in the same function like a biological pathway) related to the disease in question. For example, inflammatory disease modules are likely to show similarities with a functional module enriched for inflammatory pathways [17]. By inference, functionally related diseases tend to have similar disease modules [23]. However, modules from different diseases may (as we show in this thesis) overlap. In [24], the authors state that a phenotype often correlates with the inability of a particular functional module to perform its tasks. Thus, different combinations of genes in the same module could result in the same disease phenotype. For example, Zellweger syndrome is caused by mutations in any of at least 11 genes, where all of those genes are associated with the same process peroxisome biogenesis [24].

Modules in general are a widely observed network feature in biological networks $[2,25,26]$. For example modules have been reported in gene network of Saccharomyces cerevisiae [26], apoptosis network [27], PPI networks [2], metabolic networks [28], and many others. In order to identify modules one can choose between numerous methods [29,30]. All of those 
methods are based on a prior knowledge, which in biological contexts is often incomplete and/or noisy. This prior knowledge might be, for example, protein-protein interaction network (were both nodes and edges are not fully known $[31,32]$ ), or experimentally measured gene expression data, or combination of those two. Gene expression measured with microarrays rise doubts about experiment reproducibility and comparability [33,34,35]. On the other hand, RNA-Seq is an alternative to microarrays. This technique was shown to be superior to microarrays in terms of detection of low abundance transcripts, and is not limited by the prior design (which genes and their fragments should be targeted in the experiment) [35]. Even though technical variability has been shown to be lower in RNA-Seq compared to microarray studies [36], it is still present. Also other sources of bias in the data cannot be fully eliminated. Furthermore key problem for all models is shortage of data - the number of measured genes is usually much larger than the number of measurements [37]. Therefore individual gene-gene interactions in the network can be doubtful, and there is a need for robust concepts that can be inferred despite data limitations. Wide abundance of modules and hubs (genes with many neighbours, Fig.1, discussed below) across various biological contexts might denote that those concepts are stable network features.

However, the question in this thesis is how the same genes can be involved in the pathogenesis of different diseases. As stated above, one explanation is that same biological process (like pathway) might be affected by different gene malfunctions and therefore can lead to one or more diseases. Those malfunctions could be quantitative or qualitative. Examples of the former include differential mRNA or protein expression levels, which can be due to both genetic and epigenetic causes. Examples of the latter include genetic variants affecting protein composition, including differential splicing, which could affect protein-protein interactions [38].

Because of this complexity, disease-associated genes can be defined in multiple ways. One definition is genes associated with at least one diseaseassociated genetic variant. However, differentially expressed genes at the protein or mRNA level, may also be referred to as disease-associated. Since mRNA changes may reflect both genetic and epigenetic disease mechanisms, this thesis is focused on first identifying shared disease genes based on mRNA profiling, and secondly, mechanisms that may explain pleiotropy.

Although all cells in an individual have the same DNA, there are hun- 
dreds of different cell types. This heterogeneity is achieved by epigenetic variations. Furthermore expression quantitative trait loci (eQTL) - genomic positions that affect gene expression, have been shown to be cellor tissue specific [39]. Moreover GWAS perturbations of functional groups of genes (modules) often point to known disease-relevant cell types and tissues [40]. Further, disease genes often exhibit tissue-specific expression patterns $[18,21,41]$. Therefore, in order to identify and functionally study shared disease-associated genes it would be ideal to obtain patient samples from a tissue associated with many diseases. In this thesis project, we searched for a cell type that was both associated with many diseases and accessible for clinical studies. In order to identify such a cell type, the first project in my thesis was based on pathway enrichment analyses of all published GWAS genes. This showed that $\mathrm{T}$ cell differentiation was the most enriched pathway. This pathway is expressed in CD4+ T cells, which is the focus of my thesis.

This focus is supported by several known factors: $\mathrm{T}$ cells constantly patrol all parts of the body in order to detect, heal or combat disease processes. Therefore, any alterations in its regulation may affect other systems. For example although autoimmune diseases often affect specific organs, they might also have more systematic manifestations [42]. Examples include coeliac disease which primarily damages intestinal mucosa, but may also have neurological, psychiatric, or thyroid manifestations [42]. Moreover in [42] authors claim that most if not all of dysregulated processes involved in autoimmune diseases will in fact at some point result in T-cell activation. Indeed, $\mathrm{T}$ cells are, either primarily or secondarily, involved in allergic, autoimmune, infectious, and malignant diseases [43]. This further supports that the immune system might be a common denominator for many diseases. As an example, many shared autoimmune and inflammatory disease associated variants are specifically enriched in the active enhancer elements in stimulated T-cell subpopulations $[44,45,46]$. Another advantage of focusing on $\mathrm{T}$ cells is that their activation and differentiation are well defined and can be induced in vitro in primary cells from healthy blood donors. This allows functional studies of the effects of shared genetic or epigenetic variants on $\mathrm{T}$ cell activation or differentiation (Fig.2).

Taken together these findings support the relevance of $\mathrm{T}$ cells to study shared disease genes. In the first project of my thesis we have identified disease modules in expression profiling of published data from $\mathrm{T}$ cells from 


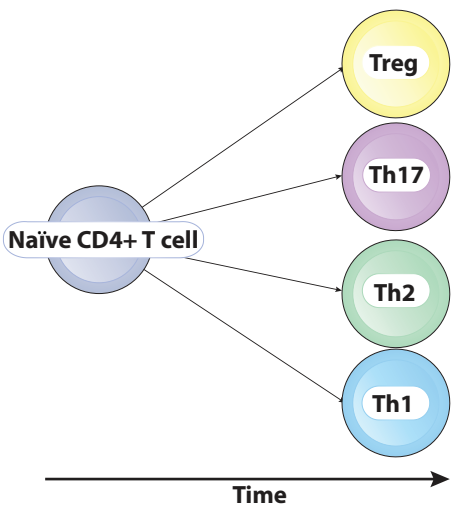

Figure 2: Conceptual model of how a Naïve T cell can differentiate into different subsets, T regulatory (Treg), and T helper (Th) cells of types 17, 2 and 1.

eight inflammatory and malignant diseases. We found that those modules in fact do overlap. These overlapping genes were also highly interconnected and formed a new module, hereafter referred to as a shared disease module [47]. We also found that the shared disease module was enriched for key cellular pathways regulating metabolism, proliferation and inflammation. In support of if its disease relevance the shared module was highly enriched for GWAS genes, primary drug targets and diagnostic markers. Variable enrichment of GWAS genes pointed to an explanation for why the same genes can be associated with different diseases. Also, different SNPs mapped to the same gene might have presumingly different effects and hereby contribute to different disease phenotypes. For example SNP rs11209026 has been associated with inflammatory bowel disease [48], and rs7517847 with Crohn's disease [49]. Both those SNPs map to the same gene - IL23R, which is known to have an important role in $\mathrm{T}$ cell functions and also proposed as a therapeutic target in inflammatory diseases [50]. rs11209026 is located in the exon of IL23R (missense SNP), whereas rs7517847 is located in intron [51], therefore provided that those are causing variants they have different effects on the IL23R gene.

However, this study was conducted based on the gene expression measured during the active disease, which may result from early causal genes. In the second project we have aimed to identify early putatively causal genes. Our hypotheses were that a) early regulators of $\mathrm{T}$ cell associated diseases could be found by defining upstream transcription factors (TFs) 
in T helper cell differentiation TF-gene regulatory network (TF-GRN); and b) such early regulators can be further prioritized by the GWAS SNP enrichment in order to identify early putatively causal $\mathrm{T}$ cell master regulators.

Here, yet again we focus on $\mathrm{T}$ cells, and specifically on $\mathrm{T}$ helper cell differentiation, for the same reason presented above - genes involved in T helper cell differentiation pathway, are the most enriched for GWAS genes. Hypothetically, a T cell based GRN should be activated early in order to combat disease, and therefore abnormalities in first steps of $\mathrm{T}$ cell differentiation might have cascading effect on other downstream $\mathrm{T}$ cell genes.

We have therefore performed time-series profiling of gene expression in four major CD4+ T-cell subpopulations differentiating from Naïve towards mature cells. Specifically, we have measured the transcriptomes of $\mathrm{T}$ helper cell type 1 (Th1), T helper cell type 2 (Th2), T helper cell type 17 (Th17), and $\mathrm{T}$ regulatory cells (Treg) at six time points. We found several genes that were differentially expressed during early Th1 versus Th2 differentiation $^{1}$. In further support of the relevance of TF-GRN we found that early Th1/Th2 transcription factors (TFs) were the class of genes most enriched for known GWAS genes. Therefore, we proceed to create a Th1/Th2 TFGRN. The time aspect is a crucial component to our experimental approach, as we aimed to identify upstream regulators of $\mathrm{T}$ helper cell differentiation. Those would intuitively change their expression very early during the cell differentiation process. Furthermore we have prioritized early TFs with many downstream targets - so called hub TFs.

The background is that previous data support that human beings can cope with a relatively big percentage of gene mutations if such mutations are located in the peripheral parts of the interactome, where the affected genes have fewer connections [22]. Peripheral genes tend to be non-essential, whereas genes located towards network centre tend to have more essential roles like tumour suppressors or oncogenes [22] and their mutations more frequently contribute to pathological consequences [22].

The importance of hubs (Fig.1) for maintaining the network topology is supported by many observations, and is in line with discussed above concept that even though individual edges in the network are doubtful hubs seem to be a robust network feature. Most networks, including cellular networks, have skewed node degree distribution (often described as scale-free) [52,53] - such networks are dominated by few key hub nodes - nodes with very

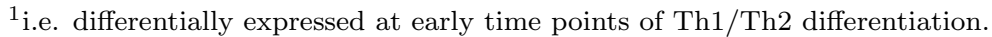


many neighbours. The existence of hubs by chance is unprobable but it is reasonable from biological point of view [37]. In general, such networks are quite robust upon random node removal - which is in line with what we observe, that healthy individuals may harbour many mutations with no disease manifestation. However when hub-genes are removed it may have catastrophic effect on the network topology [2]. This is consistent with the effects of such genes being likely to flux over the entire network causing error propagation [17]. Moreover the importance of hub-genes is supported by the fact that they are conserved and tend to evolve slower than the nonhub genes [17], and that viruses evolved to target hub-genes [54,55]. Taken together these findings led us to prioritize hub TFs in the TF-GRN.

In summary, we have hypothesized that putative shared disease regulators can be inferred from a TF-GRN of $\mathrm{T}$ helper cell differentiation, where early differentially expressed hub-TFs enriched for GWAS-identified SNPs are prioritized. We identified three such hub-TFs: GATA3, MAF and $M Y B$. This project gave us an insight into how the same 'driver' genes may be involved in multiple diseases:

Firstly - differential gene expression: we found that the three hub-TFs were differentially expressed at different levels, in different combinations and directions (up- or down-downregulation) in six out of eight studied diseases. Which might be a consequence of the SNP effect (as discussed in the next point).

Secondly - all three hub-TFs were enriched for SNPs that were associated with multiple different diseases, which means that the same gene might be affected by different SNPs, which in turn, may lead to different phenotypic effects.

Thirdly- differential splicing. In this project we have identified one probable reason why a gene gets differentially spliced in disease. We have shown an association between disease SNP and exon inclusion in GATA3 [43].

In principal, the first and last points might both be a consequence of SNPs (second point), however other factors might contribute to differential gene expression and splicing such as differential gene methylation.

For the validation of the upstream role of the three hub-TFs one would need to analyse samples from the pre-symptomatic stages of the disease. Such samples are difficult to obtain as patients generally present to the health care when they are already symptomatic. Therefore, a prospective study would be required or an access to a biobank. In the absence of the 
samples from pre-symptomatic disease stages we have hypothesized that relapsing diseases in their symptom-free phases can serve as a model of non-symptomatic disease stages. Here we concentrated on two such diseases, seasonal allergic rhinitis (SAR) and multiple sclerosis (MS). SAR is an ideal disease model as symptoms occur at the same time during the year caused by known external trigger - pollen [56]. Therefore, we hypothesized that CD4+ T cells collected from SAR patients during winter time can then serve as a proxy of the early disease stages, whereas same cells in vitro allergen challenged would then represent active disease. Another disease we have used is MS. Here we hypothesized that remission can be seen as a proxy of symptom-free early disease stage.

Our results have shown that the three TFs or their splicing variants were differentially expressed in the symptom-free phases of those two diseases, whereas TF-targets were miss-expressed in the active disease.

In this thesis to this point we have concentrated on the transcription factors as the main cell regulators, although there are others like for example epigenetic modifications or noncoding RNAs. Hyper-methylation of some genes has been reported at early event of tumorigenesis [57] as well as tumour-type specific methylation landscape has been reported [57]. Furthermore DNA methylation changes have been shown to separate allergic patients from healthy controls [58]. However as pointed before in this thesis we concentrate on mRNA expression patterns as it is believed to reflect both genetics and epigenetics. Another example of a class of molecules that might affect gene expression are noncoding RNA molecules. For example, in cancer key mutational drivers have been associated with long non-coding RNAs (lncRNAs); [59]. However lncRNAs, are thought to be downstream effectors [59]. Another example of noncoding RNA molecules includes microRNAs (miRs). Those are short ( 22nt long) noncoding RNAs that post-transcriptionally negatively regulate gene expression. It is estimated that microRNAs regulate around $60 \%$ of protein coding genes [60]. Canonically, microRNAs fine-tune mRNA expression by binding to the transcripts 3'UTR region and inducing either mRNA cleavage or causing inhibition of translation [60]. For the interaction to be present it is commonly accepted that the miR 'seed' region has to be perfectly or nearly perfectly complementary to the mRNA sequence $[60,61]$. Usually 'seed' denotes nucleotides at the $2^{\text {nd }}$ to $7^{\text {th }}$ position at the 5 ' end of the microRNA [61] and has been shown to be most conserved among the miR sequence [61]. It 
is commonly accepted that conservation may imply sequence importance because of evolutionary pressure [61]. However there is no single model describing all possible microRNA-mRNA interactions because of their heterogeneity [61].

miRs have been reported to have important functions in cell proliferation and development, differentiation, programmed cell death and stress response [62]. Furthermore, miRs are thought to be key mediators in the host response to infections, they are involved in innate and adaptive immune pathways [60]. Since miRs seem to play an important role in mediating host response to infection, their deregulation may in turn lead to susceptibility towards disease [60]. For example, Mycobacterium tuberculosis has been shown to supress miR-let-7f production leading to increased survival of this bacteria [63].

microRNA profiles in cells isolated from patients suffering from viral, bacterial or fungal infections differed from healthy controls [60]. This tendency has been also shown in vitro infected cells [60]. The crucial role of miRs in the immune system was also reported previously. They are involved in cell differentiation, development [64,65], activation [60], proliferation and apoptosis [65], cell lineage stage fate determination [60], maturation, and maintenance of immune homeostasis and regular function [66]. Changes in miR expression has been reported in a variety of human diseases, including autoimmunity, especially in $\mathrm{T}$ cell related autoimmunity [66]. For example silencing or reduction of DICER (an enzyme involved in the miRNA processing machinery) lead to reduced number of $\mathrm{T}$ cells in the thymus and periphery lymphoid tissues [66]. Furthermore, SNPs and mutations have been seen in some miRNA targeted genes and miRNA target sites, which are linked to causation and progress of some inflammatory autoimmune diseases [66].

One of the major advantages of miRs in clinical contexts is that they can be isolated from most biological fluids (extracellular miRs - ex-miRs); [60] and since it has already been proven that the ex-miRs signatures are highly predictive of an infection [60], they can serve as a possible disease markers.

Recognizing the importance of miRs, we have aimed to infer if microRNAs might have an upstream role in disease pathogenesis. It has been reported that miRs' repressive effects on GRNs are cumulative [67]. On the system level miRs can be seen as stabilizers of GRN, which makes sense as it can be shown that the wider the spread of repressions over different nodes, 
the more stable the network becomes [67]. One microRNA might regulate many mRNAs and one mRNA might be regulated by many microRNAs. Moreover, individual miRs are often seen to target proteins in the same or connected pathways [60], and are expected to act in combinations on their target genes [68]. Because of that we have decided to identify groups of miRs that cumulatively regulated the same targets - in other words we have aimed to identify miR-mRNA modules. Since targets of miRs can differ between cells [60] here again we have created cell type, and process specific microRNA-gene regulatory network (mGRN). We have taken into consideration not only sequence based miR-gene target predictions, but also miR-gene anticorrelation ${ }^{2}$ in T-cell differentiation. Furthermore we have created miR-mRNA modules - i.e. groups of miRs that are predicted to synergistically regulate same group of gene targets. We have tested disease relevance of those miR-mRNA modules in total of 11 CD4+ T-cell related diseases finding one module miss-expressed in all 15 microarray datasets studied. Moreover, this miR-mRNA module was highly enriched for disease associated genetic variants (SNPs).

Even though we haven't found evidence for the upstream role of miRs in disease pathogenesis, we have shown miR involvement in T-cell differentiation and CD4+ T-cell related diseases, which is in line with previous reports.

In summary, this thesis reveals the importance of shared-multi-disease genes and shared up-stream regulators. This work shields light on the potential explanations why the same genes might contribute to the pathogenesis of different diseases i.e. a) differential gene expression in different diseases (for example deregulation of a key $\mathrm{TF}$ would affect expression of its target genes); b) alternative splicing of a key TF may affect its target group of genes (different splice variants of the same gene might have different target genes); and c) SNPs might cause alternative splicing.

\footnotetext{
${ }^{2}$ Here we have concentrated on anticorrelation since miRs are thought to negatively regulate gene expression.
} 


\section{Materials and Methods}

In the section below summary of materials and methods is presented, concentrating on bioinformatics methods, which were in my main focus during this $\mathrm{PhD}$. For remaining information please refer to original papers and manuscript.

\section{Study subjects}

\section{PROJECT I}

1. CD4+ $\mathrm{T}$ cells from 48 patients with seasonal allergic rhinitis (SAR) stimulated with glucocorticoids (GCs). Eight of these were classified as high responders (HRs; see below for definitions) and eight as low responders (LR); SAR was defined based on a positive seasonal history, and a positive skin prick test or a positive ImmunoCap Rapid test to birch and/or grass pollen. Patients with perennial symptoms or asthma were excluded. The healthy controls did not have any history for SAR and had negative tests results;

2. CD4+ T cells from 50 patients with multiple sclerosis (MS) stimulated with humanized monoclonal antibody which binds to $\alpha 4 \beta 1$ - integrin (natalizumab-NZB). Eight of the MS patients were classified as HRs and eight as LRs (see below for definitions).

\section{PROJECT II}

1. Naïve CD4+ T cells were freshly isolated from four healthy donors and polarized towards T helper cell type 1 (Th1), type 2 (Th2), type 17 (Th17) and regulatory $\mathrm{T}$ (Treg);

2. CD4+ T cells from 10 SAR patients and 10 healthy donors. SAR and healthy subjects were defined as in project I (see above);

3. CD4+ T cells from 14 SAR patients before and during two years of treatment with immunotherapy, and six healthy donors;

4. Eight patients with symptomatic influenza A or B, which was verified with PCR experiment of nasal secretions; 
5. 10 patients with active pulmonary tuberculosis, and matched six controls from Lima, Peru;

6. Eight breast cancer patients sampled before radical surgery;

7. CD4+ T cells from 10 healthy donors and 10 MS patients diagnosed with definite relapsing-remitting MS. Patients did not undergo corticosteroids or immuno-modulatory treatment for at least two months before sample collection, and were relapse-free for at least three months.

\section{PROJECT III}

1. Naïve CD4+ T cells were freshly isolated from four healthy donors and polarized towards Th1, Th2, Th17 and regulatory T - same biological material as in project II;

2. CD4+ T cells from 10 SAR patients and 10 healthy controls stimulated with mock (PBS) or grass pollen extract for 17h; SAR was defined as in project I (see above).

\section{Ethics statement}

All studies participants provided written consent for participation.

\section{PROJECT I}

Studies were approved by ethics boars of University of Gothenburg and Linköping. Diary number: 2013/12-31, Mikael Benson, M180-07 and T13009, Jan Ernerudh.

\section{PROJECT II}

Studies were approved by ethics boars of University of Gothenburg, Lima, and Linköping. Diary number: 2013/12-31, Mikael Benson, M180-07 and T130-09.

\section{PROJECT III}

Study was approved by the ethics board of Linköping University. Diary number: 2011-292/31, Mikael Benson. 


\section{Definition of low and high responders to treatment}

Response to treatment was assessed by asking patients to mark their symptoms on a visual analogue scale. The symptoms were rhinorrhoea, congestion, and itching. The patients marked their symptoms before and after two weeks of nasal treatment. LRs/HRs were defined based on decrease in symptom scores when treated for two weeks during the pollen season.

Fifty patients with MS were treated with NZB, and classified as LRs or HRs depending on if they had had at least one relapse, or no relapse at all during the three-year follow-up period. Expression profiling was performed before starting NZB medication.

\section{GWAS data accession}

\section{PROJECT I}

GWASs data were downloaded from GWAS Catalog National Human Genome Research Institute (NHGRI). Data included 256 diseases and traits. SNPs were mapped to the closest up- and down-stream genes at the significance threshold $10^{-5}$.

\section{PROJECT II}

GWASs data were downloaded from GWAS Catalog National Human Genome Research Institute (NHGRI) on $6^{\text {th }}$ March 2014. All categories were first classified manually as disease traits (421) and non-disease traits (574). Nondisease traits were removed from further analyses. All remaining SNPs were mapped to the closest up- and down-stream gene. All genes with at least one disease SNP mapped to are referred as GWAS genes. All nominally disease associated SNPs i.e. SNPs with $P<10^{-3}$ were downloaded from [69] version $3(2014 / 03 / 06)$ for SNP frequency enrichment analyses.

\section{PROJECT III}

GWAS SNPs were obtained from GWASDB2 (version 2, October 2015) [69]. SNPs in high linkage disequilibrium (LD; r2 > 0.8, 1000 Genomes Phase 3 v5) [70] were identified with SNiPA-tool [71] (available at http://www . snipa.org, accessed October 2015). SNPs were further mapped to the genes within $5 \mathrm{~kb}$ flanking genes region. 


\section{Enrichment analyses}

\section{PROJECT I}

Pathway enrichment analyses of GWAS genes was tested using all pathways in Kyoto Encyclopedia of Genes and Genomes (KEGG) [72], Ingenuity Pathway Analysis (IPA; Ingenuity ${ }^{\circledR}$ Systems) [73], and Gene Ontology (GO) [74]; all accessed on $15^{\text {th }}$ November 2013. As a background all human genes annotated in NCBI (National Center for Biotechnology Information) were used. Mouse knockout phenotypes were downloaded from [75] on $31^{\text {st }}$ January 2013. Therapeutic target drugs and disease or prognosis markers were downloaded from IPA database. Enrichment $P$-values were calculated using Fisher's Exact Test (FET) using all human and mouse genes as background respectively. In order to control possible connectivity biases during enrichment analyses of shared disease genes we have performed permutation test of genes in STRING [76] preserving median and minimal degree to be the same as for the shared disease module. $P$-values were corrected for multiple testing with Benjamini Hochberg correction method. Size effect was calculated as fold enrichments (FE) i.e. frequency of genes in the tested set having a certain characteristic divided by the frequency of the characteristic genes among all annotated genes.

\section{PROJECT II}

Pathway enrichment analyses of GATA3, MAF and $M Y B$ predicted targets were tested with Ingenuity Pathway Analysis (IPA; Ingenuity ${ }^{\circledR}$ Systems) [73].

\section{PROJECT III}

Pathway enrichment was performed using Gene Ontology terms with DAVID using all microRNA target mRNAs in microRNA-gene regulatory network (mGRN) as background. For SNP enrichment analyses we performed permutation test ( $10^{6}$ randomizations) having variant frequency as a test statistic.

\section{Public T-cell disease data PROJECT I and II}

Public T cell related disease microarray data were downloaded from the Gene Expression Omnibus (GEO) repository on 31 $1^{\text {st }}$ December 2013 that consisted of i) unstimulated CD4 $+\mathrm{T}$ cells profiling from healthy controls 
and patients with $\mathrm{T}$ cell-related non-virus diseases; ii) at least five patient samples and controls; and iii) the patients were not undergoing drug treatment and were not symptomatic, iv) samples were not activated in vitro (GSE4588, GSE50101, GSE13732, GSE14924, GSE14317, GSE8835, GSE12079).

\section{PROJECT III}

The same public gene expression data as in project I and II were metaanalysed, plus additional three (GSE6740, GSE9927, GSE17354) that followed the same criteria as before apart from that they had to contain at least three samples per patients and controls (in contrast to the previous requirement of 5 samples per condition). microRNA microarrays followed the same criteria on $7^{\text {th }}$ June 2014 (GSE21697, GSE31629, GSE24022).

\section{Gene expression microarray data processing PROJECT I}

The GCs and NZB materials were corrected for potential batch effects using COMBAT [77], using phenotype and stimulation as covariates. All probes were mapped to the corresponding genes. If there were multiple present probes - the median probe levels were used. The LIMMA package in $\mathrm{R}$ was used to compute differentially expressed genes.

\section{PROJECT II}

Microarray data were processed as described in project I with the exception that if a gene was represented by more than one probe mean instead of median values over the probes were considered. Differential gene expression analyses were done using maSigPro in order to find differentially expressed (DE) genes between the time-series (default parameters) [78]. Early differentially expressed genes were defined as a subset of maSigPro DE genes that were further DE at $6 \mathrm{~h}$ or $24 \mathrm{~h}$, Th1 vs Th2 in either Tippets or Fishers method for combining LIMMA $P$-values. Individual genes were assumed to be DE if double-sided $P<0.05$ after correction for multiple testing with the Benjamini Hochberg procedure.

\section{PROJECT III}

Microarrays were processed and differentially expressed genes were defined as in project I. Paired test was used when possible. 


\section{Analyses of sets of genes PROJECT I}

In order to test if a set of genes was differentially expressed mean of the squares of the student $t$-test statistic was calculated and compared to random distribution obtained from permutation test $\left(10^{6}\right.$ randomizations $)$. Additional analyses were performed using the - $\log P$-values giving similar results. Small $P$-values were approximated using [79]. Fold enrichments (FEs) were calculated as described above.

\section{PROJECT II}

In order to define if a subset of genes was $\mathrm{DE}$ we have used similar method as described in project I. We have used mean $-\log 10 P$-values of the group as a permutation test-statistic $\left(10^{6}\right.$ resampling $)$. Small $P$-values estimation was done as described before in project I. Effect size of enrichment analyses was calculated as odds ratios (ORs), i.e. ratio between mean value of the test statistic in the test group and average value in is complementary group.

\section{PROJECT III}

Left-sided - $\log$ transformed Pearson's correlation $P$-value was used as test statistic for permutation test checking if a set of microRNAs and microRNAtarget mRNA were anti-correlated $\left(10^{6}\right.$ permutations $)$.

\section{Disease-associated network modules}

\section{PROJECT I}

Both the network and modules were constructed using a modified method described in [14]. All maximal cliques [80] in the human protein-protein interactions (PPI) database - STRING [81] (version using 9.03 interactions with a confidence score $\geq 0.7$ ) were assigned a weight. This weight was defined based on the differential expression analysis as a sum of the $-\log (P$-values $)$ of all genes in the clique. Furthermore permutation test was performed randomizing $P$-values for all the genes in the differential expression analysis, and the randomized weight for each clique was calculated using same method as above. In order to obtain $P$-value of each clique's weight the fraction of randomized weights was calculated that resulted in a higher value than the original, 'real' weight. Cliques that obtained $P$-value 
smaller than 0.01 were than mapped back to PPI forming module. Whole procedure was repeated for each disease resulting in a module associated to each disease. For estimation how the disease modules intersection size differs from random, all the above analysis were repeated 100 times, again randomizing $P$-values. For each of the randomization step the intersection size between randomized disease modules was calculated. Obtained 100 module intersection sizes from permutations were next compared with the 'real' intersection size. Additionally those 100 sets of disease modules were also used to identify genes present in more disease modules than expected by chance.

\section{PROJECT III}

For disease association microRNA-mRNA modules were tested for differential expression in public disease expression data (see above). For each module $P$-values were combined with the Stouffer method [82]. Module has been assumed to be disease associated if combined $P$-value was lower than 0.05 .

\section{Shared disease module validation in several human interactome databases \\ PROJECT I}

Latest versions of HPRD [83], Reactome [80], Intact [84], HI2 [84], and a high confidence database [85] were downloaded on $15^{\text {th }}$ November 2013. Shortest distances between all pairs of nodes in the shared disease module that were also present in the largest connected component (LCC) were calculated. Next 1,000 random set of genes were selected from the largest connected component preserving the same number of genes as in the overlap of shared disease module genes and LCC. $P$-values were obtained using Wilcoxon test of the mean values of the shortest paths.

\section{Classifications}

\section{PROJECT I}

Classifiers were built using LASSO with MATLAB function lassoglm(). $\lambda$ parameter was chosen from leave-one-out cross-validation at the minimum deviance. 


\section{PROJECT II}

In order to classify patients versus controls Support Vector Machine classifier was made with using MATLAB function svmtrain(). Leave-one-out validation followed by the calculation of area under ROC curve (AUC) were performed in order to assess classifier performance. AUC was estimated with MATLAB function trapz(). Expression of GATA3, MAF and MYB were tested as discriminant features, which allowed for good classification of 6 out of 8 diseases (AUC>0.85), whereas three transcription factors (TFs) downstream targets separated patients and controls with high AUC in all 8 diseases studied (AUC>0.95).

\section{Th1/Th2 regulatory region analysis PROJECT II}

Accessible DNA regions were defined by DNase peaks in Th1 and Th2 cells downloaded from Encode database. For those regions methylation expression of Naïve T-cells (NT), and 7 days polarized Th1, and Th2 cells with custom methylation microarrays (Agilent Technologies) (79,789 enhancers in total) was measured. Quantile normalization has been used. Each regulatory region was mapped to the upstream gene. In order to determine if a region is active it has been compared to the distribution of all regulatory regions - i.e. enhancer was assumed non-active if its methylation probe level was higher than two standard deviations above the average probe level. All genes with at least one active regulatory region mapped to in NT, Th1 or Th2 cells were assumed to be possibly accessible for regulation in Th1/Th2 cells. Additional GATA3 ChIP-Seq was downloaded from supplementary material in [86] - those binding sites were used to validate TF-GRN in Th1 and Th2 cells.

\section{Construction of the Th1/Th2 GRN PROJECT II}

From the list of differentially expressed (DE) genes (see above) and Th1/Th2 accessible genes a subgroup of transcription factors (TFs) was selected. List of human TFs and co-factors was downloaded from Animal TF database [87] on $1^{\text {st }}$ January 2013. Further sequence based TF-mRNA predictions (TFBS) were downloaded from [88].

Prior confidence of TF-target interaction was represented by confidence interaction matrix which for $i$-th $\mathrm{TF}$ and $j$-th target gene was defined as 
follows:

$$
P_{i j}=\left\{\begin{aligned}
\frac{m_{i}}{n}, & \text { if } \mathrm{TF} i \text { was predicted to bind gene } j \\
1+\frac{m_{i}}{n}, & \text { if } \mathrm{TF} i \text { was } \underline{\text { not predicted to bind gene } j}
\end{aligned}\right.
$$

Where $m_{i}$ denotes the number of $T F_{i}$ predicted targets.

Expression difference $(y)$ in Th1 $\left(x^{T h 1}\right)$ and Th2 $\left(x^{T h 2}\right)$ cells for $i$-th gene and each time point $t_{k}$ of polarization was defined as:

$$
y_{i}\left(t_{k}\right)=x_{i}^{T h 1}\left(t_{k}\right)-x_{i}^{T h 2}\left(t_{k}\right)
$$

The mean of forward and backward differences at the internal points was estimated as the rate of change:

$$
\dot{y}\left(t_{k}\right)=\frac{y_{i}\left(t_{k}+1\right)-y_{i}\left(t_{k}-1\right)}{2}
$$

For time evolution, for all Th1/Th2 genes, linear model of following form was used:

$$
\dot{y}\left(t_{k}\right)=\sum_{j} w_{i j} y_{i}(t)
$$

Values of $w_{i j}$ were inferred using LASSO [89] with MATLAB function glmnet() selecting $\lambda$ values from 10 -fold cross-validation using one standard error criteria.

LASSO inference formula:

$$
\min _{\left[w_{j i}\right]_{j \in T F}} \sum_{k=1}^{K}\left(\dot{y}_{i}\left(t_{k}\right)-\sum_{j \in T F}\left(w_{j i} y_{j}\left(t_{k}\right)\right)\right)^{2}+\lambda_{i} \sum_{j \in T F} P_{i j}\left|w_{j i}\right|, \forall i
$$

\section{TF-target relationship correlation analyses}

\section{PROJECT II}

The correlation analysis for the TF-target relationships for the eight public diseases analysis was carried out from geometric mean of the $P$-values of its predicted targets for each of the eight diseases, and the corresponding $P$-value of the TFs (from LIMMA). 


\section{ChIP-Seq analyses}

\section{PROJECT II}

All reads were aligned to genome version hg19 using Bowtie2 [90] (default settings). At this step technical replicates were merged. Peaks were determined using MACS14 [91], with the $P$-value cut-off of $10^{-4}$. During peak calling for GATA3, input was ignored since this sample has failed. For MAF and MYB appropriate inputs were used. All peaks were than further mapped to genes with transcription starting site in the range of $4 \mathrm{~kb}$ upstream and downstream from the peaks (BEDTools [92]). Weighted permutation test was performed in order to validate if TF-GRN-predicted GATA3, $M A F$, and $M Y B$ targets are enriched for peaks with lower peak $P$-value (higher confidence) i.e. bootstrap $P$-value was calculated using weighted mean number of peaks mapped to TF-targets as test statistic checking if it is higher than for random gene set of the same size. $10^{3}$ permutations were done. Weights were calculated as 1- geometric mean of the peaks $P$-values.

\section{Gene Regulatory Network and TFBS comparison using ChIP-Seq peak counts}

\section{PROJECT II}

For comparison of TF-GRN-predicted TF targets with only sequence based predictions (TFBS) permutation test was performed using all network genes as a background. Test statistic was defined as the ratio between the average number of peaks mapped to the TF-GRN-predicted TF targets and mean number of peaks mapped to TFBS TF targets, $10^{3}$ permutations were performed.

\section{Splice associated SNPs}

PROJECT II

All GWAS SNPs were mapped to the predicted splice regulatory sites (SRS) of GATA3, MAF, and MYB with RegRNA2.0 online tool [93]. SRS were defined as exon splicing silencer, exon splicing enhancer, intron splicing silencer, intron splicing enhancer and splicing sites. 


\section{Expression quantitative trait loci PROJECT II}

GATA3 expression quantitative trait loci (eQTL) analyses were performed as follows: both genotypes data and normalized exon counts were downloaded from the gEUVADIS repository [94]. By fitting linear equations association between genotypes and exon counts was computed. $P$-values were calculated with $F$-test. In this analyses only European samples were analysed. Here we have used Ensembl genome version GRCh37.

\section{siRNA mediated gene knock down PROJECT II}

For identification of splice variant specific targets Pearson's correlation analysis over all the 6 exon arrays were performed. All gene variants of all TF-GRN-predicted MAF targets (103 targets) were tested. Splice variant target association has been assumed if correlation $P<0.05$ and $\mathrm{FDR}<0.1$.

\section{Sublingual immunotherapy (SLIT) PROJECT II}

Subject samples were collected at the three time points: a) before treatment, immediately prior to initiation of SLIT; b) after one; and c) two years of treatment. The treatment for birch allergy was based on an 11-day progression of doses phase for Staloral ${ }^{\circledR}$ (Stallergenes SA), (from 10 to finally $300 \mathrm{IR} / \mathrm{ml}$ ). Drops were kept under patients tongue for $2 \mathrm{~min}$ before swallowing. The dosage of 240-IR was kept for 5-6 months. Next 6-months were with no treatment. All patients responded positively to treatment.

\section{Quantitative PCR (qPCR) PROJECT II}

For expression calculations comparative $\Delta \mathrm{Ct}$ method was used, having $A C T B$ as an internal control. qPCR measured gene expressions were compared using one-sided Wilcoxon test.

\section{PROJECT III}

For expression calculations comparative $\Delta \mathrm{Ct}$ method was used having GUSB and hsa-mir-423-5p as internal controls for mRNA and microRNA, respectively. 


\section{MS gene expression in relapse and remission}

\section{PROJECT II}

Meta-analyses were done of material originally published in [95] of 113 samples of MS patients and healthy controls with most of the samples being paired. In this study additional patient information not published previously was used such as the time-point for their remissions, the status of their recovery, and their treatments. This allowed for identification of patients with relapse at their first visit and remission at the second one. At both visits patients had a clinically isolated syndrome. Relapse was defined as within 90 days from first clinical symptoms, whereas remission as more than one year since last clinical symptoms occurred and where patients clinically recovered (judged by a physician). Those requirements let for identification of the subset of patients used in this study: 30 patients with remission (with 10 matched controls). Eleven of those patients were also sampled during relapse.

\section{GWAS analysis of multiple sclerosis PROJECT II}

Original data from the MS consortium study [96] consisting of genotype array of all common SNPs of $\sim 25,000$ individuals was reanalysed. SNPs mapped to GATA3, MAF and $M Y B$ with $P$-value $<0.001$ (total of 9 SNPs) were further queried at the regulome database [97] (accessed on $18^{\text {th }} \mathrm{Jun}$ 2015 ) in order to check if any of them might have regulatory effects. Analyses revealed, seven such SNPs (regulomedb score 1-6). Disease severity association of those seven SNPs was than tested in an independent study of 2,085 MS patients published in [98]. Additional, previously unpublished disease severity data was used: 252 (of 2,085) patients had severe disease variant. For significance assessment if patients with severe disease had more SNPs permutation test has been used.

\section{Construction of miR-mRNA regulatory network and module identification \\ PROJECT III}

For microRNA-mRNA regulatory network construction microRNA-mRNA sequence based predictions (TargetScan 6.0 [99] and miRanda [100]) and 
microRNA-mRNA ani-correlation analyses (Pearson's correlation, left-sided test) were combined. microRNA was assumed as a putative regulator of an mRNA if there was a predicted microRNA-mRNA interaction by both miRanda and TargetScan algorithms and if the microRNA and mRNA were significantly anti-correlated in the time series data of Th1/Th2 polarization. For module construction miRsynergy tool [101] was used with following parameters: alpha $=2$; merge.tol $=2$; density1.tol $=1 \mathrm{e}-2$, density2.tol $=5 \mathrm{e}-3$. Gene-gene interaction network was obtained from STRING 9.1 database [76]. Modified Shannon entropy score [102] was calculated using - $\log _{10}$ transformed Stouffer [82] combined $P$-values for each module and time-point in order to identify time-point specialization in the modules. 


\section{Results and Discussion}

Since the advent of Genome Wide Association Studies (GWASs), many genomic loci have been associated with more than one trait and/or disease. One striking example is $\mathrm{NOTCH}_{4}$, which has been associated with multiple, highly diverse diseases such as rheumatoid arthritis, ulcerative colitis, and lung cancer in ever smokers, age-related macular degeneration, shingles, plantar warts, and strep throat (GWAS Catalog; [103]). In contrast to the highly pleiotropic $\mathrm{NOTCH}_{4}$, another example, $\mathrm{CEP} 290$, illustrates that the same gene can have pleiotropic effects within the same organ system. Variants in this gene are associated with retinal degeneration and intellectual disability, both of which affect the nervous system [104]. Generally, disease gene pleiotropy ${ }^{1}$ has become a widely recognized phenomenon, and gave rise to the main question behind this thesis: How can the same genes may contribute to pathogenesis of different diseases?

In order to address this question, the first aim of my thesis was to define a group of genes involved in the pathogenesis of more than one disease shared disease genes. The second aim was to examine if it is possible to identify shared upstream regulator or regulators that control genes in multiple diseases. The third aim was to study potential mechanisms by which shared disease genes and regulators can be associated with different diseases.

\section{Project I: Identification of shared disease genes}

Even though each cell in our body has the same DNA sequence, tissues, organs and cell-types are highly diverse functionally and phenotypically. They express different genes at different levels. For example, LEF1 has been shown to be associated with tissue-specific functions in twelve different tissues [105]. Epigenetic factors such as DNA methylation or non-coding RNAs may also cause disease-associated changes that vary in different cell types or tissues. This complexity has two implications for the study of shared genes or their products: 1) mRNA may be an optimal starting point for such studies, because it may reflect both genetic and epigenetic variants; 2) to limit the confounding effects of cell- or tissue-specific variation in

\footnotetext{
${ }^{1}$ disease gene pleiotropy - gene association with more than one disease phenotype.
} 
mRNA expression, it may also be optimal to focus on one cell-type that is highly relevant to many diseases - i.e. a cell type whose impairing might lead, or highly contribute to, many disease phenotypes.

SNPs might affect genes in a variety of ways. In the case of complex diseases, many SNPs are located in non-coding regions (including introns) [10]. Those SNPs might affect gene expression, TF binging sites, alternative splicing, chromatin accessibility, DNA methylation, small RNAs, large intergenic non-coding RNAs (lincRNAs), RNA editing, and mRNA degradation [106]. On the other hand, intergenic SNPs might affect alternative splicing, open reading frames, amino acid inclusion leading to change of protein function. For example, around $2 / 3$ of disease missense mutations result in the perturbation of the interactome, of which $50 \%$ lead to complete loss of interactions, mainly due to protein misfolding or impaired expression [107]. The other half leads to alteration of part of the interactions [107]. However only about $7 \%$ of GWAS SNPs can be found in protein-coding DNA regions [108].

Interpretation of GWASs results should be done with caution, because of biological complexity and technical limitations. SNPs are commonly mapped to the host gene in order to identify disease associated genes via genetic variants. Intergenic SNPs are often mapped to the closest upstream and/or downstream gene. The criteria for mapping of those SNPs may have important implications for pleiotropy, which can be difficult to dissect. For example, most human genes (nearly 80\%) expressed in whole blood have a local eQTL (local variant affecting gene expression; [109]). Those eQTLs often have small effect sizes [109], and may also affect distal genes. Thus, different eQTL mapping to the same genes may have pleiotropic effects. Furthermore SNPs identified with GWASs represent all SNPs in the high linkage disequilibrium (LD) and therefore might not necessarily increase disease risk themselves but rather mark nearby DNA loci that does [108, $110]$.

As exemplified by $\mathrm{NOTCH}_{4}$, above, different genetic variants in the same gene may be one of the explanations why the same genes can be involved in multiple disease pathogenesis. However, it is also possible that the same gene and variant may have pleiotropic, but opposing, effects in different diseases. For example, SNP rs2476601 (mapped to gene PTPN22) increases risk for type I diabetes, but is protective against Crohn's disease [11].

Furthermore GWASs generally tend to identify only common genetic variants [10], which in general only explain a small proportion of the ob- 
served heritability [105]. Moreover, even though GWASs are generally genome wide - some regions are poorly covered, like for example copy number variable regions [10].

However, despite their limitations GWASs are the most comprehensive source of disease associated genetic variants. It has been shown that genetic variants identified in GWASs tend to perturb regulatory modules specific to cell types or tissues that are important for disease [40]. Therefore, we have hypothesised that a cell type expressing pathways enriched for genes with variants associated with multiple diseases, would in turn, be of relevance for multiple diseases. Therefore, we have proceeded with pathway enrichment analyses of genes to which at least one disease associated SNP have been mapped (henceforth referred to as 'GWAS genes'). This revealed the $\mathrm{T}$ helper cell differentiation pathway to be most enriched for GWAS genes (Bonferroni-corrected $P<10^{-15}$ Ingenuity Pathway Analysis-IPA [73]; $P<2 \times 10^{-6}$ Gene Ontology [74]; $P<4 \times 10^{-3}$ Kyoto Encyclopedia of Gene and Genomes [72]). Moreover, the $\mathrm{T}$ helper cell differentiation pathway was also enriched for genes annotated to diseases in Online Mendelian Inheritance in Man database [5] $\left(P<2 \times 10^{-11}\right)$. Since alleles are non-randomly associated at different loci we have also verified pathway enrichment based on all genes in linkage disequilibrium with the GWAS genes again finding $\mathrm{T}$ helper cell differentiation pathway enriched $\left(P<3 \times 10^{-7}\right)$.

However, this result might have been confounded by overrepresentation of immune-related diseases studied with GWASs. To assess this possible confounder, we manually classified diseases as immune and non-immune ${ }^{2}$, and repeated the analyses, once more finding highly significant enrichment of the $\mathrm{T}$ helper cell differentiation pathway $\left(P<1 \times 10^{-7}\right.$; IPA).

This is consistent with $\mathrm{T}$ cells having key regulatory roles in many different diseases, such as autoimmune and allergic diseases (5), atherosclerosis (6), cancer (7), and obesity (8). In malignant diseases, tumour-infiltrating $\mathrm{T}$ cells have been associated with prognosis in malignant melanoma [111] and ovarian cancer [112]. In HIV-positive patients with anal cancer, lower CD4+ T cell counts were associated with worse treatment outcome [113]. Similar to CD4+ T cells several reports associate CD8+ T cells with improved survival in different forms of cancer $[114,115,116]$. In contrast to $\mathrm{CD} 8+\mathrm{T}$ cells, FoxP3+ regulatory $\mathrm{T}$ cells, have more complex links to prognosis. In some solid tumours these cells are associated with poor prog-

\footnotetext{
${ }^{2}$ Diseases were manually classified as immune and non-immune by a medical doctor.
} 
nosis [115], while in colorectal, head and neck, and oesophageal cancers FoxP3+ Tregs are associated with good prognosis [115]. Taken together, these data support the hypothesis that profiling of $\mathrm{T}$ cells immune cells may help to understand common disease mechanisms.

For that reason and since $\mathrm{T}$ helper cell differentiation pathway is expressed in $\mathrm{CD} 4+\mathrm{T}$ cells throughout this thesis we have focused on transcriptome profiling in CD4+ T cells.

Many studies have shown that disease relevant genes are highly connected, and co-localise $[14,17,21,22]$ in the interactome forming highly interconnected modules, which, if dysfunctional may lead to disease [21,24]. The main advantage of a module-based approach is that modules are thought to prioritise limited numbers of highly disease-relevant genes. Even if not all genes in the disease-associated gene module are differentially expressed (corrected for multiple testing $P<0.05$ ) the majority of genes would exhibit altered expression levels. In other words, we assume that a modest but consistent change of expression of many interacting genes might be as, or even more, important for disease pathogenesis as a pronounced, big change of an individual gene.

Therefore, we have proceed to identify disease modules based on expression profiling data from eight diseases (inflammatory and malignant), namely: four inflammatory diseases (allergy [(GEO) accession GSE50101], multiple sclerosis [GSE13732], rheumatoid arthritis [GSE4588], and systemic lupus erythematosus [GSE4588]), and four malignant or proliferative diseases (acute myelogenous leukemia [GSE14924], adult T cell leukemia [GSE14317], chronic lymphocytic leukemia [GSE8835], and hypereosinophilic syndrome [GSE12079]). Data sets choice criteria are described in the materials section. For all eight diseases we have identified genes that were significantly differentially expressed when comparing patients versus healthy controls. Next, we mapped these genes to their protein products in the Protein-Protein Interaction (PPI) network (STRING [102]). In agreement with previous studies of disease-associated genes we found that those genes instead of being dispersed in the human PPI were rather co-localised, forming modules (highly connected structures). This lead to identification of eight disease modules each consisting of 1,215 to 1,933 genes (interconnected differentially expressed genes).

Because of the heterogeneity of the studied diseases, we expected that the corresponding modules would be dispersed in the PPI network. Instead, 


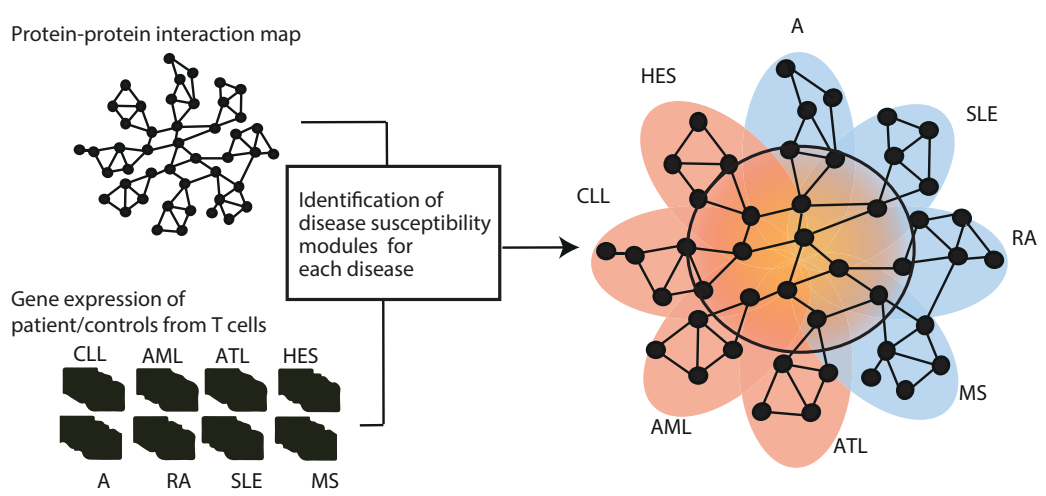

Figure 3: The shared disease module (marked using a solid black circle) identified by analysis of expression profiling data from eight CD4+ T cell-associated diseases: allergy (A); acute myelogenous leukemia (AML); adult T cell leukemia (ATL); chronic lymphocytic leukemia (CLL); hypereosinophilic syndrome (HES). Black nodes represent proteins, lines possible gene interactions. From Gustafsson et al., Integrated genomic and prospective clinical studies show the importance of modular pleiotropy for disease susceptibility, diagnosis and treatment. Genome Med 6, 17 (2014). Reprinted with permission.

they tended to overlap (Fig.3). Consequently, we assumed that shared disease genes lie in the intersection of those modules. Those genes in the intersection of disease modules were generally highly interconnected forming a yet another module - here referred to as a 'shared disease module'. The shared disease module consisted of 158 genes with 7,144 interactions between genes compared to 376 expected for 158 random genes $\left(P<10^{-300}\right)$. In order to confirm this finding we have analysed 5 additional versions of the human PPI networks (Materials and Methods) showing that the 158 shared disease genes had lower average shortest path between each other when compared to random sets of 158 genes $\left(P<10^{-3}\right.$ in four versions and $P<0.011$ for the fifth version).

The shared disease module was enriched for key cell pathways like metabolism, proliferation etc., as well as enriched for known disease markers and therapeutic targets $\left(P<10^{-46}\right.$ and $P<10^{-28}$ respectively), indicating its importance not only in healthy cells but also in active disease.

Modules in general are associated with robustness of biological systems $[28,117]$. In general high connectivity is often linked to redundancy compensating loss-of-function mutations [117]. However same property might lead to cascading effect of local failures [117]. Indeed sparser net- 
works are shown to be more robust [118]. Interestingly in [117] it is shown that modules exposed to greater environmental variation are generally more robust and contain less interactions [117]. On the other hand more essential modules (i.e. modules enriched for essential genes ${ }^{3}$ ) are located central to the cell and are more densely connected [117]. Examples of internal processes include: transcription initiation, ribosomal subunit, mRNA processing modules. On the other hand cell wall organization, endosomal transport are examples of external cell processes less connected and not enriched for essential genes [117]. Even though this study is focused on Saccharomyces cerevisiae authors note similar results for other organisms including bacteria and roundworm and even identified similarities to the computational systems security [117]. Therefore, those findings might be generally applicable. In fact, we also observed that the shared disease module, that we believe is of importance for many immune related diseases, was highly interconnected with 19 times more interactions between genes than expected by chance (see above), which might explain why this specific part of the PPI is shared by many diseases.

However, although encouraging those results cannot be conclusive about the casual role of the genes in the shared module. Therefore, we proceeded to analyse a mouse knockout database, which showed that many of the shared module genes, when knocked out, lead to multiple phenotypes and diseases in mice $\left(P<10^{-50}\right)$. The most significant mice phenotypes were abnormality of the hematopoietic and immune systems, and tumorigenesis. We also found a GWAS and cancer gene enrichment among shared disease genes $\left(P<10^{-15}\right.$ and $P<10^{-41}$ respectively). Further, although the shared module genes were only based on analysis of eight diseases, we also found that those genes were generally enriched for associations to diseases and traits analysed with GWASs (and not only immune-related diseases and cancer; $P<4 \times 10^{-3}$ ). All of those results support the general relevance of the shared disease module genes for involvement in disease pathogenesis.

The main limitation of this module-based approach is that it depends on the definition. Even though the core shared module genes should remain the same, the module boundaries are not strictly defined and can be altered upon change of module definition. For example, the shared module could be defined as genes shared by at least two diseases, as well as genes belonging to all eight disease modules (as used throughout this project). In this context

\footnotetext{
${ }^{3}$ Here essential genes denotes genes whose knock-out leads to cell death.
} 


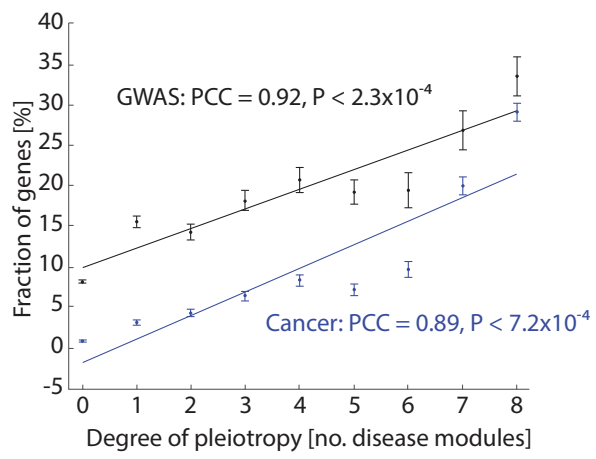

Figure 4: Genes in the shared disease module were divided into subgroups based on the number of disease modules they belong to. In the plot Pearson's correlation is presented between number of modules genes in the subgroup belongs to (x-axis) and fraction of GWAS and cancer genes in the respective gene subgroup (y-axis). From Gustafsson et al., Integrated genomic and prospective clinical studies show the importance of modular pleiotropy for disease susceptibility, diagnosis and treatment. Genome Med 6, 17 (2014). Reprinted with permission.

we found it important to test if the shared disease module enrichment in GWAS and cancer genes depended on the definition. We found a strong correlation between degree of gene 'sharedness' - i.e. number of disease modules a gene belongs to, and fraction of GWAS (PCC $=0.91, P<4 \times$ $10^{-4}$ ) and cancer genes (PCC $=0.94, P<2 \times 10^{-4}$ ), (Fig.4). In other words, genes belonging to a larger number of disease modules, were more enriched for GWAS genes. This finding supports that shared disease module enrichment in both GWAS genes and cancer genes does not depend on the exact module definition.

It is also important to keep another potential limitation in mind - modules are defined using models of the human PPI network, in which many protein-protein interactions are missing [119].

Here, in this project we also examined the possibility of using shared disease genes to predict treatment outcome in order to further strengthen the clinical importance of those genes. We carried out a prospective study of 48 patients with Seasonal Allergic Rhinitis (SAR) (Materials and Methods). SAR patients were classified as high- or low-responders (HR and LR respectively) to a common drug, glucocorticoids (GCs), by clinical specialists (Materials and Methods). In order to mimic the molecular responses to treatment with this drug, CD4 $+\mathrm{T}$ cells were isolated from peripheral 
A

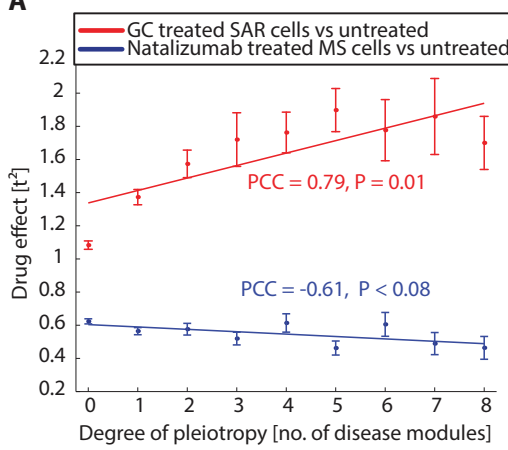

B

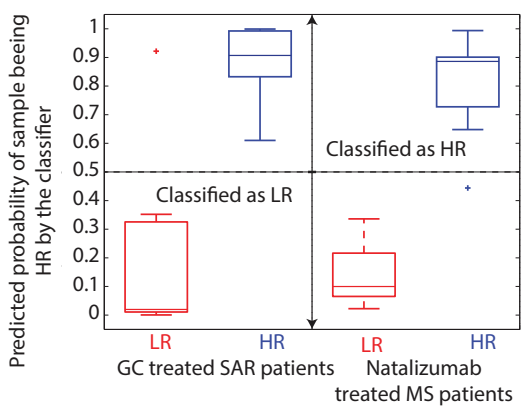

Figure 5: Treatment response based on shared or disease-specific genes. (A) Genes in the shared disease module were divided into subgroups based on the number of disease modules they belong to. Treatment effect on mRNA expression was calculated based on the gene differential expression in treated vs untreated cells squared student $t$-test values. CD4+ T cells isolated from seasonal allergic rhinitis (SAR) patients treated with Glucocorticoid (GC) (red), CD4+ T cells from patients with multiple sclerosis (MS) treated with natazulimab (blue). In the plot Pearson's correlation is presented between mean treatment \pm standard error of the average effect on mRNA expression in the respective gene subgroup and number of modules genes in the subset belongs to; (B) Classification of high and low responders to treatment in SAR and MS based on the shared disease genes (belonging to at least two disease modules) or disease-specific genes respectively. In the figure box plots are showing the median, inner quartile range, whiskers and outliers of the predicted probability of a subject being a high responder. Subjects were divided in to groups of high responders (HRs-blue) and low responders (LRs -red) after treatment. Here classification border is presented with the horizontal black line at 0.5. From Gustafsson et al., Integrated genomic and prospective clinical studies show the importance of modular pleiotropy for disease susceptibility, diagnosis and treatment. Genome Med 6, 17 (2014). Reprinted with permission.

blood from these patients during symptom-free periods (outside of pollen season). Next, the cells were stimulated in vitro with allergen extract and GCs. Based on gene expression microarray analyses we noticed an increased likelihood of a response to GCs among 'more shared' genes - i.e. genes belonging to more disease modules ( $\mathrm{PCC}=0.79, P=0.0011$; Fig.5A).

Furthermore, we created a classifier that correctly separated high- and low-responders $\left(P<3 \times 10^{-4}\right.$, Fig.5B). The classifier was built based on 311 genes affected by the drug (found as differentially expressed) and shared by at least 2 diseases (belonging to at least 2 disease modules).

We performed a similar study in patients with another relapsing inflammatory disease, multiple sclerosis (MS). These patients were treated with 
a drug specifically targeting MS, natalizumab, and classified as HR or LR (Materials and Methods). In order to study their molecular responses to the drug, we first extracted CD4 $+\mathrm{T}$ cells from the patients during remission (symptom-free periods). Next, we treated the CD4 $+\mathrm{T}$ cells with nataluzimab and analysed them with gene expression microarrays.

In contrast to SAR, we found that MS disease-specific genes were targeted by the drug rather than shared disease genes $(\mathrm{PCC}=-0.61, P=0.079$; Fig.5A). Therefore, we hypothesized that MS disease specific genes (belonging uniquely to MS disease module) would serve as better discriminators when constructing classifier to separate HR and LR. Indeed, a classifier made based on $28 \mathrm{MS}$ specific genes that were affected by natalizumab correctly stratified $\mathrm{HR}$ and $\mathrm{LR}\left(P<3 \times 10^{-4}\right.$, Fig.5B).

\section{Project II: Identification of the upstream regulators}

In the section above, SNP enrichment in shared genes identified by expression profiling supported causality. Also, since those SNPs differed between patients with different diseases, this provided a potential explanation for why the same genes can contribute to pathogenesis of different diseases. However, the differentially expressed genes were identified during active disease, which may be secondary to early causal genes. Therefore, in the second project we aimed to identify early regulatory genes.

One approach may be to link disease-associated traits and diseases that have a shared genetic architecture [120]. For example, variants in the gene $I K Z F 1$ are associated with both mean corpuscular volume (trait) and acute lymphoblastic leukemia (ALL; disease) [120]. Increase of average corpuscular volume is being noted before ALL is diagnosed [120] and therefore the trait is assumed to increase disease risk. This would support the causal role of the shared genes. However, this is an inference with many possible confounders. Another approach may be based on using known protein interactions to infer up-stream regulators of genes that are differentially expressed during active disease [121]. However, this approach is limited to only direct upstream gene interactors and therefore might not be sufficient in search for causal regulators.

Identification of causal genetic drivers of human diseases has also been presented in [122]. Here authors tested candidate copy number variation genes whose copy number is informative of gene expression and have predictive value of transcription factors (TFs) activity. However, this approach 
is limited by the requirement of a large number of sample-matched gene expression and genetic variant profiles.

In contrast, we hypothesized that upstream master regulators can be identified in a healthy $\mathrm{T}$ helper cell differentiation process. The background to this hypothesis is our previous finding that the $\mathrm{T}$ helper cell differentiation pathway is highly enriched for GWAS genes, as discussed above. Also, the $\mathrm{T}$ helper cell differentiation pathway is possible to mimic in vitro, using well-defined methods. This allows time-series analysis of the differentiation processes, starting with early stages. Based on this background, we proceeded to profile differentiation of four major CD4+ T cell subsets namely $\mathrm{T}$ helper cell type 1 (Th1), T helper cell type 2 (Th2), T helper cell type 17 (Th17), and T regulatory cell (Treg), from Naïve to mature cells in an in vitro model. We measured gene expression profiles with microarrays at six time points $(6 \mathrm{~h}, 24 \mathrm{~h}, 3$ days, 6 days and 8 days) in four biological replicate biological experiments.

Subsequently, we identified that early Th1 and Th2 transcription factors (TFs, that exhibit altered gene expression early in the differentiation process, i.e. at 6 and/or 24h; Fig.6) were the most enriched for disease associated genes (GWAS genes; $\mathrm{OR}=2.7, P=1.0 \times 10^{-7}$ ).

TFs are one of the key gene expression regulators in cells. Since one TF might regulate expression of many downstream genes errors due to, for example, disease-associated SNPs, would propagate through the signalling cascade altering TF-target gene expression. In order to identify such upstream key regulators we constructed a healthy TF-Gene Regulatory Network (TF-GRN) of Th1/Th2 differentiation.

A TF-GRN is a collection of TFs and their predicted gene-targets. It can be graphically represented as a set of nodes (genes) and edges (interactions) (Fig.1).

Network robustness and wiring might be altered by disease gene activity changes due to genetic or environmental factors, which in turn might lead to the change of the network output [104]. Commonly networks were representative of a static time point, and thereby missing insights into process dynamics [104]. In this project we have partially addressed this issue by introducing time-series transcriptome profiling of differentiating $\mathrm{T}$ cells. Time in general is an important factor. Therefore, we used time-series gene expression profiling of Th1/Th2 differentiation and Transcription Factor Binding Sites predictions (TFBS) to construct a TF-Gene Regulatory Net- 


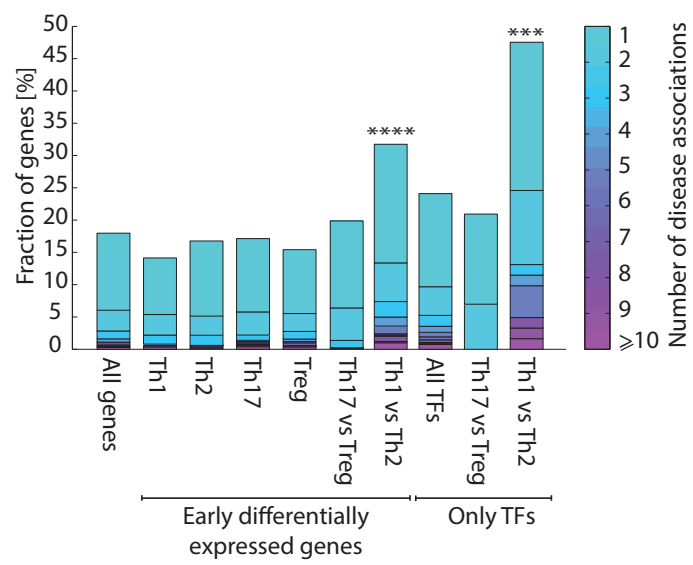

Figure 6: Differentially expressed genes in time series microarrays enrichment in GWAS genes (genes with at least one disease-associated SNPs identified by GWASs mapped to). Each T cell subset ("Th1", "Th2", "Th17", and "Treg") represent genes differentially expressed between the 6 and 24 hours of polarization in each cell type respectively. Enrichment $P$-values were obtained with Fisher's exact test $\left(* * * * P<1.0 \times 10^{-12}, * * * P<1.0 \times 10^{-6}\right)$. The number of disease associations for a gene are represented by the colour. From Gustafsson and Gawel et al., A validated gene regulatory network and GWAS identifies early regulators of T cell-associated diseases. Sci Transl Med 7, 313 ra178 (2015). Reprinted with permission from $A A A S$.

work (TF-GRN). We hypothesized that genes with methylated upstream regulatory regions are unlikely to be regulated by a $\mathrm{TF}$, and therefore we have also incorporated DNA methylation profiling.

Hub-proteins are assumed to be key players in dynamic networks (networks were network topology changes over time), and are found to often perform many functions [104]. Such multi-functionality might be seen as a gene product containing many domains with separate functions and/or perform tissue-specific functions [104]. Therefore, impairing such a gene may affect an abundance of other genes activity in one and/or in multiple different tissues and cell types. Interestingly, we found that all TFs associated with a disease via at least one SNP (GWAS TFs) had on average 3.7 times more targets than non-GWAS TFs (TFs with no mapped disease SNPs; Fig.7A).

Consequently, we hypothesized that 'master' TF regulators of T helper cell differentiation would be those TFs that regulate many downstream genes (so called hub-TFs). Indeed, we found that among the top 11 TFs 
A

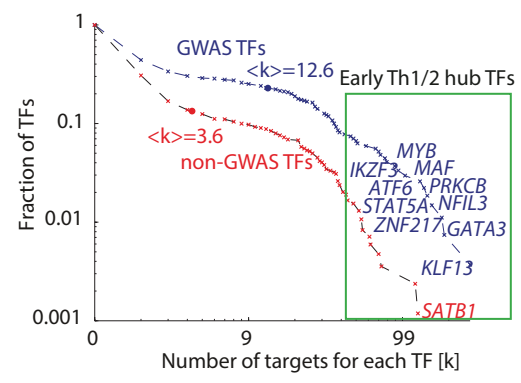

\section{B}

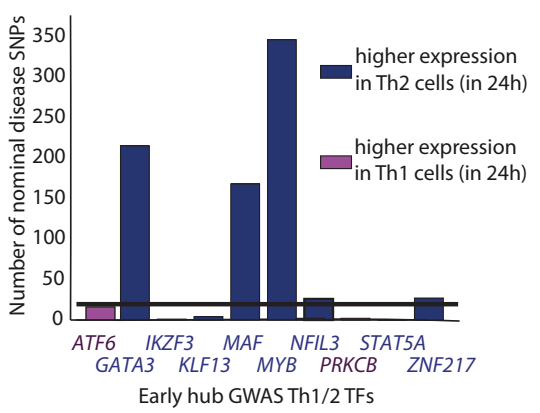

Figure 7: Transcription factors (TFs) with the highest number of TF-GRNpredicted targets were highly enriched for GWAS SNPs. (A) Curves present GWAS TFs (blue) and non-GWAs TFs (red) distribution (reverse cumulative) of the number of targets for each TF. Names of top 11 TFs with the highest number of predicted targets are presented in the figure; (B) GWAS SNP enrichment of the top 10 GWAS TFs with highest number of predicted targets. The black solid line represents the background level of all disease-associated genes. From Gustafsson and Gawel et al., A validated gene regulatory network and GWAS identifies early regulators of T cell-associated diseases. Sci Transl Med 7, $313 r a 178$ (2015). Reprinted with permission from $A A A S$.

with the highest number of TF-GRN-predicted downstream targets, 10 were GWAS TFs. Furthermore, 91\% of all the nominally disease-associated SNPs (genome-wide association of $P<10^{-5}$ ) in all of the 10 GWAS hub-TFs were mapped to GATA3, MAF and $M Y B\left(\mathrm{OR}=9.22, P=6.6 \times 10^{-3}\right.$; Fig.7B). Since these hub-TFs that were most enriched for GWAS SNPs, and therefore more likely to have casual disease roles, we focused our further studies on these three TFs.

We have validated the TF-GRN-predicted TF-target interactions with ChIP-Seq experiment of GATA3, MAF and MYB. Using this technology, we analysed to which sites the three TFs bound in differentiated human Th1 and Th2 cells.

For all the three TFs, the ChIP-Seq identified binding sites were significantly enriched for GRN predicted targets $\left(\mathrm{OR}_{G A T A 3}=7.30, P_{\text {GATA3 }}<\right.$ $10^{-81}, \mathrm{OR}_{M A F}=1.92, P_{M A F}<10^{-22}, \mathrm{OR}_{M Y B}=3.17, P_{M Y B}<10^{-27}$; Fig.8).

Moreover, siRNA-mediated knockdowns of GATA3 and MAF in Th2 cells further supported the TF-GRN TF binding sites prediction accuracy as the knockdown affected genes showed significant enrichment of 
A

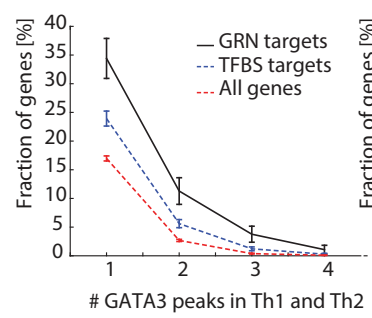

B

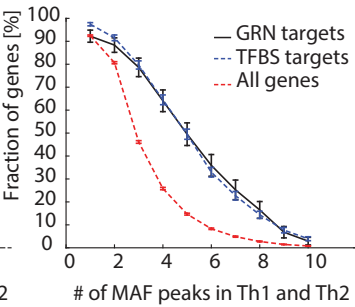

C

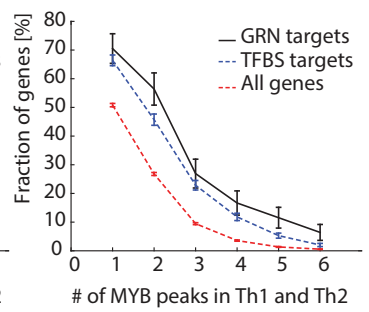

Figure 8: GATA3 (A), MAF (B), and $M Y B(\mathbf{C})$ predicted targets in Th1 and Th2 binding enrichment identified with ChIP-Seq experiment. The $\mathrm{x}$-axis represents the fraction of targets with a minimum ChIP-Seq count using the inferred targets (upper black curve), the publicly available predicted transcription factor bindings TFBS (middle blue curve), and all genes (lower red curve). From Gustafsson and Gawel et al., A validated gene regulatory network and GWAS identifies early regulators of T cell-associated diseases. Sci Transl Med 7, $313 r a 178$ (2015). Reprinted with permission from AAAS.

TF-GRN-predicted early targets compared to all genes $\left(\mathrm{OR}_{\text {GAT } A 3}=2.22\right.$, $\left.P_{G A T A 3}=2.9 \times 10^{-3} ; \mathrm{OR}_{M A F}=3.45, P_{M A F}=4.5 \times 10^{-3}\right)$, as well as to publicly available predicted TF binding sites only.

In order to test the clinical relevance of GATA3, MAF and $M Y B$ in $\mathrm{T}$ cell associated diseases we first performed pathway analyses of TF-GRNpredicted targets of all three TFs showing enrichment for several diseaserelevant pathways including cell activation and differentiation pathways, as well as diabetes, viral response, and cancer related pathways.

Here in this project we have not only identified possible disease drivers, but also three possible explanations why the shared disease genes may cause different diseases: A) shared master regulators might be deregulated at diverse levels and in different directions, or combinations, in multiple diseases; B) different SNPs at different positions might affect same gene in diverse ways; C) differential gene splicing.

The above results supported that we had identified three putative major, shared disease drivers. However, further analyses also supported two possible explanations for why the same genes can cause different diseases: 1) differential expression of the same genes; 2) SNPs might affect alternative splicing.

In support of the first explanation, we found that the same three TFs were differentially expressed in six out of eight diseases (publicly available 


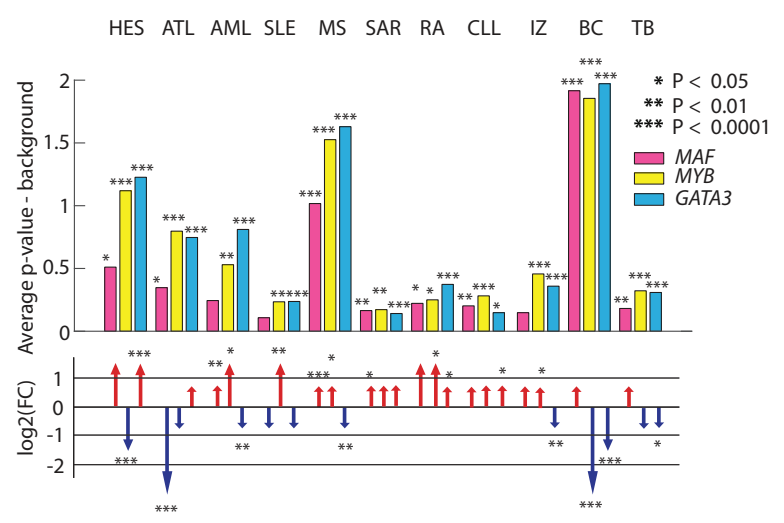

Figure 9: GATA3, $M A F$ and $M Y B$ transcript and predicted targets differential expression in multiple diseases. (Upper) Bars mark the difference in the average $P$-values TF-GRN-predicted targets of GATA3, MAF and $M Y B$ compared to all genes $\left({ }^{*} P<0.05,{ }^{* *} P<0.01,{ }^{* * *} P<0.0001\right.$ from permutation test) showing that TF-GRN-predicted targets of the three TFs are generally more affected by disease than non-target genes (have lower $P$-values; patients compared with healthy donors) in nine T cell-related diseases: hyper eosinophilic syndrome (HES), adult T cell leukemia/lymphoma (ATL), acute myeloid leukemia (AML), systemic lupus erythematosus (SLE), multiple sclerosis (MS), seasonal allergic rhinitis (SAR), influenza (IZ), breast cancer (BC), and tuberculosis (TB); (Lower) log2 fold changes $[\log 2(\mathrm{FC})]$ of the expression of each $\mathrm{TF}$ in patients compared to controls are represented by the arrows. Up-facing and down-facing arrows depict log2(FC) $>0$ and $\log 2(\mathrm{FC})<0$, respectively. From Gustafsson and Gawel et al., A validated gene regulatory network and GWAS identifies early regulators of $T$ cell-associated diseases. Sci Transl Med 7, $313 r a 178$ (2015). Reprinted with permission from $A A A S$.

microarray experiments; Materials and Methods; Fig.9).

We also found that most of the TF-GRN-predicted targets of all the three TFs (GATA3, $M A F$ and $M Y B$ ) were differentially expressed in all eight diseases (Fig.9). We have made similar observation in three additional original expression profiling studies of CD4+ T cells in breast cancer, tuberculosis and influenza (Fig.9; ad. A).

This might suggest that even though a TF is not differentially expressed itself its function might be altered so that its target genes exceed differential expression. That might be a result of protein misfolding, altered amino acid content, or by differential splicing ${ }^{4}$. All of those errors might be due

\footnotetext{
${ }^{4}$ Standard microarrays are not designed to distinguish between splice variants and therefore a gene might seem as not differentially expressed when in fact expression profiles of its splice variants are shifted.
} 
to the presence of SNPs. As we have shown GATA3, MAF and $M Y B$ are highly enriched for multiple disease associated SNPs. Thus, different SNPs associated with the same gene may lead to different disease phenotypes, through different mutations [107]; (ad. B).

In fact, there is a possibility that some of the SNPs in the nearest surrounding of the three TFs may have an impact on the transcriptional regulation and/or post-transcriptional regulation of those TFs. Indeed, we have found several regulatory SNPs (based on rSNPBase - a database with SNP regulatory annotations; [123]) in linkage disequilibrium with GWAS SNPs. Regulatory SNPs (rSNPs) are located in regulatory regions like proximal and distal transcriptional regulation sites inside elements associated with DNA accessibility, in the RNA binding proteins-associated regions, or SNPs affecting microRNA-mRNA interference. Indeed, we have found 14 disease associated SNPs with a predicted regulatory effect and 252 disease SNPs in LD block with rSNPs (106 for GATA3, 61 for $M A F$ and 85 for $M Y B$ ). We have therefore analysed all known SNPs (not only disease associated) downloaded from the UCSC database [124] and found many in the splice regulatory motif regions to be in linkage disequilibrium (LD) with GWAS SNPs mapped to GATA3, MAF or $M Y B$. Furthermore, in order to test possible regulatory role of those SNPs, for all three TFs we have predicted splice regulatory motif regions, using a tool called RegRNA 2.0 [93]. Splice regulatory motifs are exonic and intronic splicing enhancer and silencers, splicing sites or open reading frames. This led us to identify 29 SNPs for GATA3; 6 SNPs for $M A F$; and 46 for $M Y B$ that might affect splicing events. Since $M Y B$ has many splice-variants, and for $M A F$ there was no RNA-Seq data available, for exon eQTL analyses we have prioritized GATA3. GATA3 exists in 2 splicing variants that differ only in exon number 4 , which makes it an interesting example to study SNP effects on exon inclusion (see Materials and Methods). We have identified one such example where SNP was affecting the splicing of GATA3 (Fig.10).

Therefore, we proceeded to test the three TFs splice variants potential upstream role during pre-symptomatic stages of diseases where we have used two relapsing diseases as models. In summary, our analyses revealed that splice variants of those key three TFs were miss-expressed in remission (symptom-free phase of disease) whereas their predicted targets were deregulated in relapse (active disease). Thus, differential splicing is a specific example of why the same gene might be involved in the pathogenesis 


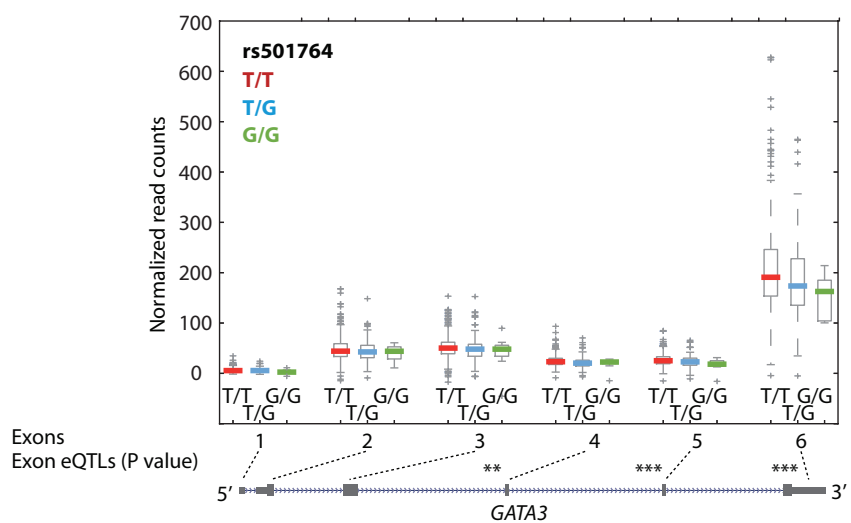

Figure 10: Expression quantitative trait loci (eQTL) analysis of the exons of GATA3. In the plot there are presented normalized RNA sequencing (RNA-Seq) counts across all six GATA3 exons. Each exon counts are further divided by the genotypes of the variant rs501764. Asterisks denotes significant exon differential expression across these genotypes $\left({ }^{*} P<0.01\right.$, $\left.{ }^{* * *} P<0.001\right)$. From Gustafsson and Gawel et al., A validated gene regulatory network and GWAS identifies early regulators of T cell-associated diseases. Sci Transl Med 7, $313 \mathrm{ra178}$ (2015). Reprinted with permission from $A A A S$.

of multiple diseases (ad. C).

Ideally, we would validate importance of GATA3, MAF and $M Y B$ in early disease pathogenesis by studying initially healthy subjects that later on develop disease. Since patients generally present to health care when they are symptomatic, one would need to conduct a study following thousands of healthy individuals over decades. Such study would be demanding both cost- and time-wise. Instead, here we hypothesized that symptom free phases of relapsing diseases could serve as models of pre-symptomatic disease stages. Here, we have studied Seasonal Allergic Rhinitis (SAR) and Multiple Sclerosis (MS) as models of such stages.

Analyses of 10 un-stimulated CD4+ T cell from MS patients in symptomfree phase (during remission) and 10 healthy controls showed significant downregulation of GATA3 splice variant 2, in patients compared to healthy controls $(P=0.019)$. Those results encouraged us to collect samples in a prospective gene expression study of MS patients seen both during relapse (active disease) and remission (symptom-free). Our analyses not only confirmed significant decrease of GATA3 during remission compared to con- 
trols, but also revealed a decrease in remission compared to relapse. Moreover, we have noted significant differential expression of GATA3, MAF and $M Y B$, TF-GRN-predicted targets during active disease (relapse) compared to controls $\left(P_{G A T A 3}<10^{-12} ; P_{M A F}=5.3 \times 10^{-3}, P_{M Y B}=1.6 \times 10^{-4}\right.$ ).

Further analyses of the MS consortium GWAS study, which included $\sim 25,000$ patients and controls showed significantly MS-associated SNPs that could be linked to all three TFs $\left(P_{M A F}=1.9 \times 10^{-5}, P_{M Y B}=5.8 \times 10^{-6}\right.$, and $\left.P_{G A T A 3}=6.6 \times 10^{-5}\right)$. Intriguingly, all three TFs were among top $1 \%$ most enriched genes for MS-associated SNPs $\left(P=3 \times 10^{-6}\right)$.

Another disease with symptom-free stages is SAR. Here, CD4+ T cells isolated from patients outside of pollen season were stimulated with allergen in vitro. We have hypothesized that unstimulated cells would represent symptom-free disease stages whereas allergen-stimulated cells would serve as a proximity to active disease stage.

For that purpose we have collected samples from 10 SAR patients and 10 healthy controls. We have profiled splice variant expressions with exon arrays. Differential expression analyses showed that splice variants of all three TFs were miss-expressed in the symptom-free disease stage $(P<0.05$; unstimulated cells) whereas their TF-GRN-predicted targets were DE in active disease $(P<0.0001$; allergen challenged cells $)$ when compared with healthy controls. Further strengthening their putative role as possible key disease drivers we have found that during asymptomatic stage all measured $M Y B$ splice variants, MAF splice variant2 (NM_001031804.2) and GATA3 splice variant 1 (NM_001002295.1) were differentially expressed (Fig.11A).

A combination of the average expression levels of the three TFs splice variants separated patients from controls with high accuracy $(\mathrm{AUC}=0.83$, $P=2.9 \times 10^{-3}$, Fig.11B). Moreover same score correlated significantly with symptom severity in patients $(\mathrm{PCC}=0.67, P=0.019$; Fig.11B).

To further validate our findings we have replicated the results in an independent material consisting of 14 patients and 6 healthy controls, where the above mentioned score again separated patients and controls with high accuracy $(\mathrm{AUC}=0.77, P=0.039$ ). This suggests the potential of the three TFs as for disease prediction and disease severity markers.

Furthermore we have asked whether we could functionally analyse the effects of splice-variants. For that reason we have performed siRNA-mediated gene silencing experiment followed by Th2 polarization and exon microarray splice variant expression profiling. Since GATA3 splice variants differ in 
A

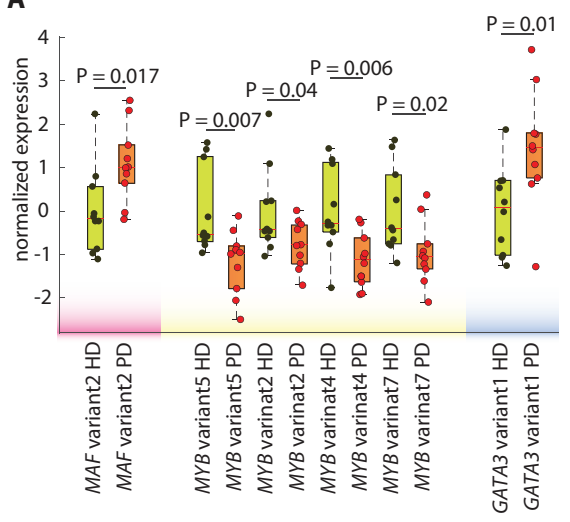

B

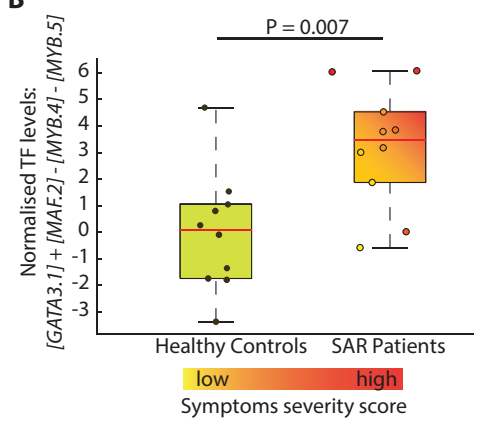

Figure 11: Splice variant differential expression of GATA3, $M A F$ and $M Y B$. (A) Exon microarray measured- GATA3, $M A F$ and $M Y B$ splice variant profiles in unchallenged cells of 10 seasonal allergic rhinitis patients (PD) and 10 healthy controls (HD). Circles denotes measurements; (B) Classifier of seasonal allergic rhinitis patients versus controls built based on the normalized sum of the differentially expressed variants of GATA3, MAF, and $M Y B$ (discriminative score). This discriminative score correlates highly with the symptom severity score. In the figure circles denotes individuals where with green colour healthy subjects are marked; yellow marks patients with low symptom severity; orange marks patients with medium symptom severity score; and red indicates patients with high symptom severity score. From Gustafsson and Gawel et al., A validated gene regulatory network and GWAS identifies early regulators of $T$ cell-associated diseases. Sci Transl Med 7, 313 ra178 (2015). Reprinted with permission from AAAS.

only one nucleotide of one exon and since $M Y B$ has multiple splice variants here we have concentrated on $M A F$ for which we were able to bioinformatically predict and experimentally verify siRNA targeting one specific $M A F$ splice variant - namely splice variant 2 (differentially expressed in the asymptomatic stage of SAR). In this experiment knockdown efficiency of $M A F$ splice variant 2 was $38.5 \%, M A F$ splice variant 1 was $1.7 \%$. We have found that $63 \%$ (65 out of 103) of TF-GRN-predicted MAF targets were affected by the knockdown (Fig.12). Moreover those genes also had lower $P$-values in the symptomatic SAR stage $\left(P<10^{-5}\right)$.

$M A F$ splice variant 2 predicted targets (TF-GRN-predicted targets affected by siRNA knockdown) were enriched for cell programed death, intracellular signal transduction, regulation of protein metabolic process, and response to growth factor (Gene Ontology pathways enrichment analyses). This further strengthens the possible importance of $M A F$ in disease patho- 


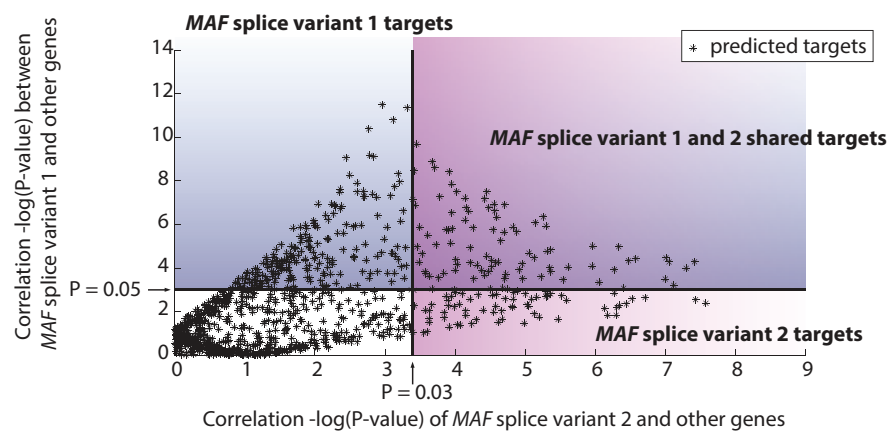

Figure 12: MAF splice variant specific targets. Stars represent TF-GRNpredicted $M A F$ targets. $M A F$ splice variant specific targets were identified using Pearson's correlation analyses between $M A F$ splice variant 1 and 2 and TF-GRNpredicted targets in MAF siRNA mediated knockdown experiment. From Gustafsson and Gawel et al., A validated gene regulatory network and GWAS identifies early regulators of T cell-associated diseases. Sci Transl Med 7, 313 ra178 (2015). Reprinted with permission from AAAS.

genesis.

Another advantage of SAR as a model disease is that allergic patients can undergo treatment (immunotherapy) in order to achieve tolerance to allergen. We have followed 14 patients over 2 years of their treatment. Splice variants expression patterns were measured at 3 time points: before immunotherapy, after 1 year and after 2 years.

We found that the therapy gradually normalised the expression of the three TFs. After 2 years of treatment TF expression in patients was comparable with healthy controls (Fig.13). This finding further supports the importance of GATA3, MAF and $M Y B$ in SAR.

Generally, this project gives an insight into possible disease regulations, and reasons why the same genes may be involved in pathogenesis of multiple diseases - here shown in example of differential splicing of master TFs in two diverse diseases: seasonal allergic rhinitis and multiple sclerosis. One limitation of this study is that master regulators were identified based on the healthy TF-GRN. During disease new disease hub TFs might emerge, which we wouldn't find in this model.

Moreover, we have tested deregulation of the three TFs in approximations of early disease stages, namely symptom-free stages of two relapsing diseases (MS and SAR). We don't know if such approximations are relevant. One validation option would be to analyse samples from biobanks 


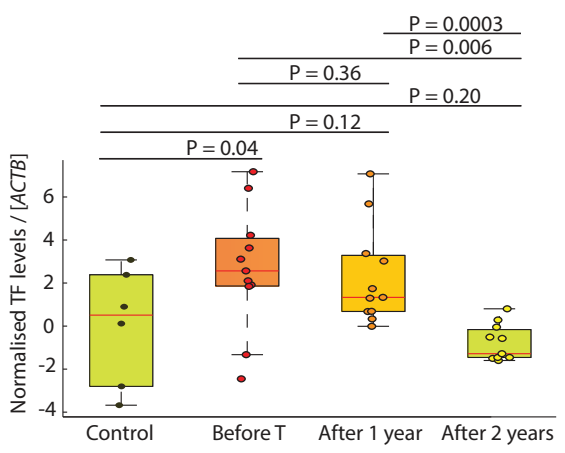

Figure 13: Change of normalized mean splice variant expression of GATA3 splice variant 1, MAF splice variant 2, MYB splice variant 4, and $M Y B$ splice variant 5 , over immunotherapy ( $\mathrm{T}$ ) before, after 1 and 2 years of treatment compared to healthy controls. From Gustafsson and Gawel et al., A validated gene regulatory network and GWAS identifies early regulators of $T$ cell-associated diseases. Sci Transl Med 7, $313 r a 178$ (2015). Reprinted with permission from AAAS.

- biorepositories that store biological samples collected from large number of humans for use in research. However samples volume is limited, and therefore isolation and analyses of $\mathrm{T}$ cells in those samples are complicated. Another option is to conduct a prospective study where one should ideally analyse samples coming from individuals that do not have a disease at the time of sample collection but develop it later in life. However, this approach is very complex as we don't know beforehand who is going to develop disease, and therefore large cohorts of initially healthy individuals would need to be followed over time. Moreover, it's currently unknown when to expect gene expression changes before symptoms occur. That time would most probably differ depending not only on the specific disease but also interpersonally. Therefore, one would need to perform measurements relatively often which would increase study costs and complexity. In the absence of such samples, using symptom-free phases of diseases suggests a direction for further studies - here we have reduced number of possible hypothesis from hundreds to three - namely GATA3, MAF and MYB.

In this project, we have concentrated on transcription factors as early TFs were most enriched for variants identified by GWASs. Due to the nature of TFs (regulating gene expression) we have prioritized hub-TFs meaning TFs with the highest number of targets. However, as discussed below, there have been reports that apart from hub nodes other type of 
nodes in the interactome are of importance in disease.

Most biological networks have skewed node degree distribution (often referred to as scale-free networks) [2]- meaning that they are dominated by a few key hub nodes. In this type of networks hub nodes in the networks have been proven to be crucial for maintaining network integrity as discussed above. Due to the fact that hub nodes have a very high number of neighbours [2]. That in fact might be an advantage in case of drug design where targeting one gene with drug many have a therapeutic effect on multiple downstream genes. However, an attack on the hub nodes can be extremely destructive. Interestingly, viruses evolved to target hub nodes [125]. As much as hub nodes are of considerable importance in scale-fee networks there are other network features that may imply node importance.

For example, betweeness centrality is a measure that mirrors how many shortest paths between other nodes lead through a given node. Nodes with high betweenness score can be seen as the main connectors within network topology [104]. The higher betweenness centrality the bigger destructions within network would occur upon node removal, and therefore more likely to result in a disease phenotype $[24,126,127,128]$.

On the other hand, disconnectivity reflects how important a node/edge or a set of nodes/edges are for maintaining the communication between pairs of nodes in the network [128]. This measure allows for assessment of topological redundancy.

Having all of those, and other, options in mind, one could search for key, putatively disease driving nodes (genes) in the network in multiple ways.

Apart from the variety of node types from the network topology perspective there are other gene regulators in cells that could be taken into account - like microRNAs that may have a key role in disease pathogenesis.

\section{Project III: microRNAs in $\mathrm{T}$ helper cell differentiation and in $\mathrm{T}$ cell related diseases}

MicroRNAs were previously shown to be associated with multiple diseases [63, $129,130,131,132]$, even though individual microRNAs weakly repress their targets [67]. Thus, their impact on most of their targets often results in no phenotypic effect [67]. One hypothesis is that the role of microRNAs lies in system stabilization, and that the repressive effects of microRNAs on GRN stability is cumulative [67]. This hypothesis explains the wide spread of microRNA targets over multiple mRNAs without substantial target expres- 


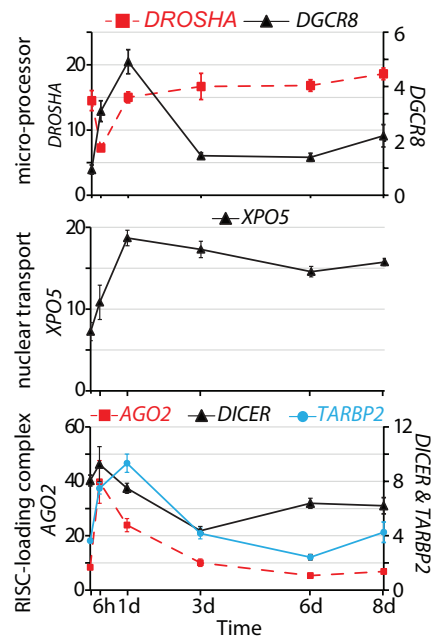

Figure 14: Average expression profiles of microRNA processing machinery over time in CD4+ T cells Naïve T cells differentiation towards mature Th1 and Th2 cells.

sion change (negative feedback loops and wide spread of targets are more efficient in maintaining system stability [67]). Moreover, testing one single microRNA hypothesis assumes that there is no redundancy in the system for phenotype control [67]. Therefore, we have proceed by analysing groups of microRNAs predicted to regulate shared group of target genes.

In this project, we have again focused on $\mathrm{T}$ helper cell differentiation process as the shared point of multiple diseases. Since Th1 versus Th2 differentially early expressed genes show the highest enrichment of GWAS genes among other cell types and comparisons (apart from early TFs discussed above; Fig.6), we again focused on differentiation of those two cell types.

Analyses of the previous time series mRNA profiling of differentiating Th1 and Th2 cells revealed early expression level change of microRNA processing machinery suggesting an important role of microRNAs in that process and therefore possible importance in disease progression. Both DROSHA and DGCR8 - core components of microRNA processing machinery together with parts of RISC complex: AGO2, DICER and TARBP2, and microRNA transport machinery (XPO5) showed expression changes (Fig.14).

Encouraged by those findings we proceeded to profile expression of micro- 
RNAs in the same setting, and in the same biological material used for analysing mRNA expression. Namely, we have polarized Naïve CD4 + T cells toward Th1 and Th2 cells in vitro. We have measured 800 microRNAs expression profiles at six time points $(0 \mathrm{hr}, 6 \mathrm{hr}, 24 \mathrm{hr}, 3$ days, 6days and 8 days). We have found 256 microRNAs to be expressed (detected in more than $50 \%$ of the samples) during differentiation.

Again, using the same principals as for TFs, we constructed a microRNAGene Regulatory Network (mGRN). mGRN was constructed based on the microRNA-gene target predictions and anti-correlation of microRNAs and mRNAs in time series of maturing Th1 and Th2 cells from the Naïve state over all 44 samples. The mGRN consisted of 174,592 edges (interactions) out of which 1,182 were microRNA-mRNA interactions.

Existing tools for microRNA-target predictions are not robust, mainly due to the high complexity of the microRNA-target regulation process [61] and by knowledge incompleteness.

In this project, we incorporated predictions made with two different algorithms, namely miRanda [100] and TargetScan [99]. miRanda has been shown to be very sensitive in comparison to other tools at the price of precision [61]. TargetScan on the other hand has higher precision [61]. Here sensitivity was defined in two ways: a) as percentage of experimentally supported microRNA predicted targets and b) as a proportion of correctly predicted microRNA targets to total correct microRNA-mRNA interactions (two different studies). Precision on the other hand was defined as proportion of correctly predicted microRNA targets to total predicted microRNAmRNA interactions [61].

There are several differences between those tools. The most significant difference is that TargetScan assumes perfect complementarity in the seed region, whereas miRanda allows for mismatches. That may to some extent explain the low sensitivity of TragetScan since, in animals, strict complementarity between target site within mRNA sequence and microRNA is rare [61]. Furthermore, both miRanda and TargetScan are generally based on microRNA sequence complementarity in the 3'UTR (untranslated region) of mRNA. However microRNA target sites can be also found in 5'UTR and ORFs $[60,61]$.

Since a group of microRNAs may regulate a shared group of genes and pathways we have then created microRNA-mRNA modules (groups of microRNAs that are predicted to regulate connected group of mRNAs) 

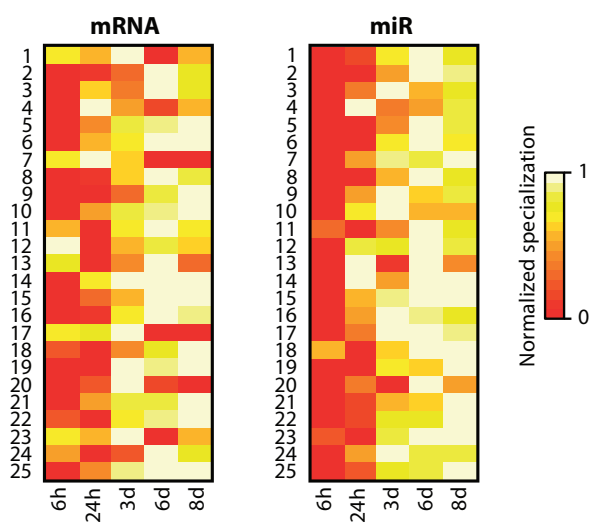

Figure 15: Normalized specialization of microRNAs and mRNAs in modules presented in heatmaps was calculated using modified Shannon's entropy score.

using mirsynergy tool [101]. We have identified 25 such modules. In contrast to our primary hypothesis that microRNAs might have upstream role in Th differentiation the majority of the modules had late time-point specificity, especially at the microRNA level (Fig.15).

To get an idea of the role of the mRNAs in the created modules we have performed pathway-enrichment analyses. We have found that modules 2,8 , 9 and 22 were most enriched $(P<0.05)$ for GO terms. Those terms were related to glycosylation (2), metabolism (8) and Wnt signalling (9 \& 22), respectively.

In order to investigate modules associations with diseases we analysed 11 CD4+Tcell associated diseases from public repositories namely: acute myeloid leukaemia (AML), human immunodeficiency virus infection (HIV), multiple sclerosis (MS), hypereosinophillic syndrome (HES), Sézary syndrome (SeS), adult $\mathrm{T}$ cell leukaemia/lymphoma (ATL), type 1 diabetes (T1D), chronic lymphoid leukaemia (CLL), seasonal allergic rhinitis (SAR), rheumatoid arthritis (RA) and systemic lupus erythematosus (SLE). All modules were differentially expressed in at least one disease $\left(P<10^{-6}\right)$. Strikingly one module (no 8) was DE in all 15 studied datasets (Fig.16). Surprisingly some diseases, including AML, HIV, MS, HES and ATL, show a degree of similarity at the mRNA level as the same modules are differentially expressed in all those diseases (modules 1-8,10,14,17,21-23,25). Whereas other diseases like T1D, CLL, SAR and HIV at the microRNA level were highly associated $\left(P<10^{-6}\right)$ with only module 8 . 


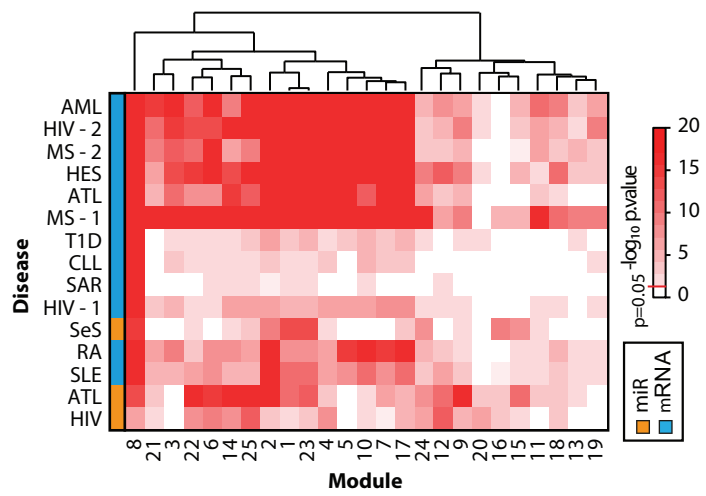

Figure 16: Heatmap of microRNA-mRNA modules associations with 11 diseases: Sézary syndrome (SeS), adult T cell leukemia (ATL), human immunodeficiency virus (HIV), rheumatoid arthritis (RA), chronic lymphocytic leukemia (CLL), type-1 diabetes (T1D), hypereosinophilic syndrome (HES), multiple sclerosis (MS), acute myeloid leukemia (AML), systemic lupus erythematosus (SLE), seasonal allergic rhinitis (SAR).

In further support of the importance of module 8 we found that it contains 10 microRNAs with known disease association to $\mathrm{T}$ cell related diseases like Sézary syndrome [129], multiple sclerosis [133], myasthenia gravis [134] and many cancers $[135,136]$.

Moreover, we have performed GWAS gene enrichment analyses of the modules finding that number of enriched disease terms ranged from 1 for modules 15 and 20, to 160 for module 8. Notably module 8 was enriched for $\mathrm{T}$ cell related diseases like SLE, Diabetes, HIV, and terms related to allergy: 'Allergic Rhinitis'; 'Atopy'; 'Asthma and Hay fewer'; 'Eosinophilic Esophagitis' and 'Self-reported Allergy' $\left(P<1 \times 10^{-5}\right)$. Generally for 12 out of 25 modules (including module 8) we have noted significant overlap between disease association based on both expression and genetic variants (GWAS; $P<0.05$ ).

Since two independent analyses suggested involvement of module 8 in allergy we have proceed to validate $\mathrm{mGRN}$ predicted edges in a prospective study of CD4+ T cells isolated from 10 healthy controls, and 10 SAR patients (samples collected out-side of the pollen season) stimulated with allergen or diluent (control) in vitro for $17 \mathrm{~h}$. This time point was chosen in order to capture early microRNA-mRNA dynamics. Both microRNAs and mRNAs were profiled with microarrays. MicroRNA-mRNA mGRN- 
predicted interactions within the module 8 were present in the new material as they were higher anti-correlated than expected by chance over all samples $\left(\mathrm{OR}=1.19 ; P=2.4 \times 10^{-4}\right)$. Moreover predicted interactions were present in both healthy controls and patients $\left(\mathrm{OR}_{\text {control }}=1.11 ; P_{\text {control }}=1.0 \times 10^{-11}\right.$; $\left.\mathrm{OR}_{\text {patient }}=1.17 ; P_{\text {patient }}=1.3 \times 10^{-23}\right)$.

Moreover, we have found that module 8 was significantly differentially expressed at both microRNA and mRNA level comparing patients and controls during an active disease (CD4+ T cells stimulated with allergen).

In summary, we have found strong microRNA-disease associations, however in contrast to primary hypothesis we haven't found an evidence for the upstream disease role of microRNAs. However current knowledge about microRNAs contains many unknowns and uncertainties. This means that there is possibility that other than widely accepted negative miR-gene regulation mechanisms might occur in early $\mathrm{T}$ cell differentiation. Which means that further studies are warranted before one can reject upstream disease miR hypothesis.

For example, microRNAs were shown to enhance translation and transcription [60], which has not been taken into account in this study. In [137] authors presented an example of miR-363-3 that enhances gene expression by binding to AU-rich regions. However, this regulation is contextdependent as it occurs in the cell-cycle arrested cells but not in proliferative cells. On the other hand, in [138] it has been shown by the example of miR-373 that by binding to complementary sites within gene's promoter regions, gene expression is promoted rather than repressed. However, not all genes with complementary sites in promoter regions are in fact positively regulated suggesting that this regulation is also context- dependent [138].

Another aspect of putative microRNA role in disease pathogenesis is their possible role in cell to cell communication. Extracellular microRNAs can be extracted from most biological fluids [60]. Although their function is currently largely unknown, there is growing evidence that ex-miRs are involved in disease pathogenesis. For example ex-miRs profiles has been shown to be predictive of infection [60]. Furthermore, there are reports showing that ex-miRs can be passed between leukocytes $[139,140,141]$; suggesting their role in cell to cell communication. Further strengthened by reports in [142] where authors show that the ex-miRs produced in Treg cells are causing repression of Th1 cell proliferation in mouse [142]. This gives another hint of the putative upstream role of microRNAs in disease, 
since immunological studies have shown that many immune-related diseases are not only a result of gene mutation or differential expression but also are characterized by elevated number of $\mathrm{T}$ cells and disproportion of $\mathrm{T}$ cell subsets [10].

Moreover, microRNAs might also regulate gene alternative splicing. It has been shown that knockdown and overexpression of microRNA processing machinery (AGO1, AGO2, and DICER1) leads to impairment in exon inclusion $[143,144]$. Targeting an intronic region of the FN1 pre-mRNA with a siRNA resulted in local chromatin remodelling and altered splicing of the adjacent exon [143]. Moreover, siRNAs targeting the pre-mRNAs of SMN2 and $D M D$ were capable of inducing either exon inclusion or exon skipping at therapeutically relevant exons [145]. In [143] authors have found evidence that siRNA targeting intragenic regions may affect alternative splicing though elongation inhibition. However, more studies are required in order to confirm or refute this hypothesis.

Here we have focused on the role of single molecular measure (mRNA and microRNA) to identify disease 'sharedness'. However to fully understand disease pathogenesis it would require comprehensive analyses of multiple sources of evidence, like not only gene-gene or microRNA-gene interactions but also epigenetic modifications, regulations of posttranscriptional modifications, shared environmental factors, affected tissues, cell type proportions and interactions, organs etc. $[146,147,148]$. 


\section{Concluding Remarks}

This thesis aimed to identify shared disease genes and shared disease regulators as well as identification of potential mechanisms that may explain how the same genes may contribute to pathogenesis of multiple diseases.

I hold that the direction of studying disease similarities has many advantages, including understanding of disease mechanisms and inter-individual variability in both disease development and response to treatment. Moreover, studies of shared disease mechanisms may reveal opportunities for drug repositioning.

As an example, using principles from [149] in an ongoing project, we have identified a drug targeting genes proximal to the shared disease gene module. Even though this drug is primary used in treatment of hyperlipidaemia, we have successfully repurposed it to treat rheumatoid arthritis in mouse (data not shown).

However, one shouldn't underestimate the power of disease specific genes. For example, in some diseases the shared disease genes may be the core of the disease but the disease-specific genes are the disease drivers directing disease pathogenesis towards specific disease.

In summary, this work can be seen as another step towards understanding shared disease mechanisms. However, many more extensive studies are required before these mechanisms can be exploited for diagnostic and therapeutic purposes. 


\section{Bibliography}

[1] L. H. Hartwell, J. J. Hopfield, S. Leibler, and A. W. Murray. From molecular to modular cell biology. Nature, 402(6761 Suppl):C47-52, 1999 .

[2] A. L. Barabsi and Z. N. Oltvai. Network biology: understanding the cell's functional organization. Nat Rev Genet, 5(2):101-13, 2004.

[3] X. Wang, E. Dalkic, M. Wu, and C. Chan. Gene module level analysis: identification to networks and dynamics. Curr Opin Biotechnol, 19(5):482-91, 2008.

[4] J. L. Badano and N. Katsanis. Beyond mendel: an evolving view of human genetic disease transmission. Nat Rev Genet, 3(10):779-89, 2002 .

[5] Online mendelian inheritance in man database. https://omim.org/.

[6] N. Risch and K. Merikangas. The future of genetic studies of complex human diseases. Science, 273(5281):1516-7, 1996.

[7] S. Sivakumaran, F. Agakov, E. Theodoratou, J. G. Prendergast, L. Zgaga, T. Manolio, I. Rudan, P. McKeigue, J. F. Wilson, and H. Campbell. Abundant pleiotropy in human complex diseases and traits. Am J Hum Genet, 89(5):607-18, 2011.

[8] C. Cotsapas, B. F. Voight, E. Rossin, K. Lage, B. M. Neale, C. Wallace, G. R. Abecasis, J. C. Barrett, T. Behrens, J. Cho, P. L. De Jager, J. T. Elder, R. R. Graham, P. Gregersen, L. Klareskog, K. A. Siminovitch, D. A. van Heel, C. Wijmenga, J. Worthington, J. A. Todd, D. A. Hafler, S. S. Rich, M. J. Daly, and FOCiS Network of Consortia. Pervasive sharing of genetic effects in autoimmune disease. PLoS Genet, 7(8):e1002254, 2011.

[9] C. Cotsapas and D. A. Hafler. Immune-mediated disease genetics: the shared basis of pathogenesis. Trends Immunol, 34(1):22-6, 2013.

[10] A. Zhernakova, C. C. van Diemen, and C. Wijmenga. Detecting shared pathogenesis from the shared genetics of immune-related diseases. Nat Rev Genet, 10(1):43-55, 2009. 
[11] Y. R. Li, J. Li, S. D. Zhao, J. P. Bradfield, F. D. Mentch, S. M. Maggadottir, C. Hou, D. J. Abrams, D. Chang, F. Gao, Y. Guo, Z. Wei, J. J. Connolly, C. J. Cardinale, M. Bakay, J. T. Glessner, D. Li, C. Kao, K. A. Thomas, H. Qiu, R. M. Chiavacci, C. E. Kim, F. Wang, J. Snyder, M. D. Richie, B. Flat, Frre, L. A. Denson, S. D. Thompson, M. L. Becker, S. L. Guthery, A. Latiano, E. Perez, E. Resnick, R. K. Russell, D. C. Wilson, M. S. Silverberg, V. Annese, B. A. Lie, M. Punaro, M. C. Dubinsky, D. S. Monos, C. Strisciuglio, A. Staiano, E. Miele, S. Kugathasan, J. A. Ellis, J. E. Munro, K. E. Sullivan, C. A. Wise, H. Chapel, C. Cunningham-Rundles, S. F. Grant, J. S. Orange, P. M. Sleiman, E. M. Behrens, A. M. Griffiths, J. Satsangi, T. H. Finkel, A. Keinan, E. T. Prak, C. Polychronakos, R. N. Baldassano, H. Li, B. J. Keating, and H. Hakonarson. Meta-analysis of shared genetic architecture across ten pediatric autoimmune diseases. Nat Med, 21(9):1018-27, 2015.

[12] N. J. Fredriksson, L. Ny, J. A. Nilsson, and E. Larsson. Systematic analysis of noncoding somatic mutations and gene expression alterations across 14 tumor types. Nat Genet, 46(12):1258-63, 2014.

[13] B. Alaei-Mahabadi, J. Bhadury, J. W. Karlsson, J. A. Nilsson, and E. Larsson. Global analysis of somatic structural genomic alterations and their impact on gene expression in diverse human cancers. Proc Natl Acad Sci U S A, 113(48):13768-13773, 2016.

[14] F. Barrens, S. Chavali, A. C. Alves, L. Coin, M. R. Jarvelin, R. Jrnsten, M. A. Langston, A. Ramasamy, G. Rogers, H. Wang, and M. Benson. Highly interconnected genes in disease-specific networks are enriched for disease-associated polymorphisms. Genome Biol, 13(6):R46, 2012.

[15] J. Lim, T. Hao, C. Shaw, A. J. Patel, G. Szab, J. F. Rual, C. J. Fisk, N. Li, A. Smolyar, D. E. Hill, A. L. Barabsi, M. Vidal, and H. Y. Zoghbi. A protein-protein interaction network for human inherited ataxias and disorders of purkinje cell degeneration. Cell, 125(4):801$14,2006$.

[16] S. D. Ghiassian, J. Menche, D. I. Chasman, F. Giulianini, R. Wang, P. Ricchiuto, M. Aikawa, H. Iwata, C. Mller, T. Zeller, A. Sharma, P. Wild, K. Lackner, S. Singh, P. M. Ridker, S. Blankenberg, A. L. 
Barabsi, and J. Loscalzo. Endophenotype network models: Common core of complex diseases. Sci Rep, 6:27414, 2016.

[17] A. L. Barabsi, N. Gulbahce, and J. Loscalzo. Network medicine: a network-based approach to human disease. Nat Rev Genet, 12(1):56$68,2011$.

[18] A. Reverter, A. Ingham, and B. P. Dalrymple. Mining tissue specificity, gene connectivity and disease association to reveal a set of genes that modify the action of disease causing genes. BioData Min, 1(1):8, 2008.

[19] K. Lage, N. T. Hansen, E. O. Karlberg, A. C. Eklund, F. S. Roque, P. K. Donahoe, Z. Szallasi, T. S. Jensen, and S. Brunak. A large-scale analysis of tissue-specific pathology and gene expression of human disease genes and complexes. Proc Natl Acad Sci U S A, 105(52):20870-5, 2008.

[20] K. Lage, K. Mllgrd, S. Greenway, H. Wakimoto, J. M. Gorham, C. T. Workman, E. Bendsen, N. T. Hansen, O. Rigina, F. S. Roque, C. Wiese, V. M. Christoffels, A. E. Roberts, L. B. Smoot, W. T. Pu, P. K. Donahoe, N. Tommerup, S. Brunak, C. E. Seidman, J. G. Seidman, and L. A. Larsen. Dissecting spatio-temporal protein networks driving human heart development and related disorders. Mol Syst Biol, 6:381, 2010.

[21] M. Kitsak, A. Sharma, J. Menche, E. Guney, S. D. Ghiassian, J. Loscalzo, and A. L. Barabsi. Tissue specificity of human disease module. Sci Rep, 6:35241, 2016.

[22] L. Garcia-Alonso, J. Jimnez-Almazn, J. Carbonell-Caballero, A. VelaBoza, J. Santoyo-Lpez, G. Antiolo, and J. Dopazo. The role of the interactome in the maintenance of deleterious variability in human populations. Mol Syst Biol, 10:752, 2014.

[23] J. Menche, A. Sharma, M. Kitsak, S. D. Ghiassian, M. Vidal, J. Loscalzo, and A. L. Barabsi. Disease networks. uncovering diseasedisease relationships through the incomplete interactome. Science, 347(6224):1257601, 2015. 
[24] K. I. Goh, M. E. Cusick, D. Valle, B. Childs, M. Vidal, and A. L. Barabsi. The human disease network. Proc Natl Acad Sci USA, 104(21):8685-90, 2007.

[25] C. D. Truong and Y. K. Kwon. Investigation on changes of modularity and robustness by edge-removal mutations in signaling networks. BMC Syst Biol, 11(Suppl 7):125, 2017.

[26] Mika Gustafsson, Michael Hrnquist, and Anna Lombardi. Comparison and validation of community structures in complex networks. Physica A: Statistical Mechanics and its Applications, 367:559576, 2006.

[27] S. Nafis, K. Ponnusamy, M. Husain, R. K. Singh, and R. N. Bamezai. Identification of key regulators and their controlling mechanism in a combinatorial apoptosis network: a systems biology approach. Mol Biosyst, 12(11):3357-3369, 2016.

[28] P. Holme. Metabolic robustness and network modularity: a model study. PLoS One, 6(2):e16605, 2011.

[29] S. Vlaic, T. Conrad, C. Tokarski-Schnelle, M. Gustafsson, U. Dahmen, R. Guthke, and S. Schuster. Modulediscoverer: Identification of regulatory modules in protein-protein interaction networks. Sci Rep, 8(1):433, 2018.

[30] M. Jalili, T. Gebhardt, O. Wolkenhauer, and A. Salehzadeh-Yazdi. Unveiling network-based functional features through integration of gene expression into protein networks. Biochim Biophys Acta, 2018.

[31] T. Rolland, M. Taan, B. Charloteaux, S. J. Pevzner, Q. Zhong, N. Sahni, S. Yi, I. Lemmens, C. Fontanillo, R. Mosca, A. Kamburov, S. D. Ghiassian, X. Yang, L. Ghamsari, D. Balcha, B. E. Begg, P. Braun, M. Brehme, M. P. Broly, A. R. Carvunis, D. ConveryZupan, R. Corominas, J. Coulombe-Huntington, E. Dann, M. Dreze, A. Dricot, C. Fan, E. Franzosa, F. Gebreab, B. J. Gutierrez, M. F. Hardy, M. Jin, S. Kang, R. Kiros, G. N. Lin, K. Luck, A. MacWilliams, J. Menche, R. R. Murray, A. Palagi, M. M. Poulin, X. Rambout, J. Rasla, P. Reichert, V. Romero, E. Ruyssinck, J. M. Sahalie, A. Scholz, A. A. Shah, A. Sharma, Y. Shen, K. Spirohn, S. Tam, A. O. Tejeda, S. A. Trigg, J. C. Twizere, K. Vega, J. Walsh, M. E. Cusick, Y. Xia, A. L. Barabsi, L. M. Iakoucheva, P. Aloy, J. De Las Rivas, 
J. Tavernier, M. A. Calderwood, D. E. Hill, T. Hao, F. P. Roth, and M. Vidal. A proteome-scale map of the human interactome network. Cell, 159(5):1212-1226, 2014.

[32] U. Stelzl and E. E. Wanker. The value of high quality proteinprotein interaction networks for systems biology. Curr Opin Chem Biol, 10(6):551-8, 2006.

[33] E. Marshall. Getting the noise out of gene arrays. Science, 306(5696):630-1, 2004.

[34] L. Shi, L. H. Reid, W. D. Jones, R. Shippy, J. A. Warrington, S. C. Baker, P. J. Collins, F. de Longueville, E. S. Kawasaki, K. Y. Lee, Y. Luo, Y. A. Sun, J. C. Willey, R. A. Setterquist, G. M. Fischer, W. Tong, Y. P. Dragan, D. J. Dix, F. W. Frueh, F. M. Goodsaid, D. Herman, R. V. Jensen, C. D. Johnson, E. K. Lobenhofer, R. K. Puri, U. Schrf, J. Thierry-Mieg, C. Wang, M. Wilson, P. K. Wolber, L. Zhang, S. Amur, W. Bao, C. C. Barbacioru, A. B. Lucas, V. Bertholet, C. Boysen, B. Bromley, D. Brown, A. Brunner, R. Canales, X. M. Cao, T. A. Cebula, J. J. Chen, J. Cheng, T. M. Chu, E. Chudin, J. Corson, J. C. Corton, L. J. Croner, C. Davies, T. S. Davison, G. Delenstarr, X. Deng, D. Dorris, A. C. Eklund, X. H. Fan, H. Fang, S. Fulmer-Smentek, J. C. Fuscoe, K. Gallagher, W. Ge, L. Guo, X. Guo, J. Hager, P. K. Haje, J. Han, T. Han, H. C. Harbottle, S. C. Harris, E. Hatchwell, C. A. Hauser, S. Hester, H. Hong, P. Hurban, S. A. Jackson, H. Ji, C. R. Knight, W. P. Kuo, J. E. LeClerc, S. Levy, Q. Z. Li, C. Liu, Y. Liu, M. J. Lombardi, Y. Ma, S. R. Magnuson, B. Maqsodi, T. McDaniel, N. Mei, O. Myklebost, B. Ning, N. Novoradovskaya, M. S. Orr, T. W. Osborn, A. Papallo, T. A. Patterson, R. G. Perkins, E. H. Peters, R. Peterson, et al. The microarray quality control (maqc) project shows inter- and intraplatform reproducibility of gene expression measurements. Nat Biotechnol, 24(9):1151-61, 2006.

[35] S. Zhao, W. P. Fung-Leung, A. Bittner, K. Ngo, and X. Liu. Comparison of rna-seq and microarray in transcriptome profiling of activated t cells. PLoS One, 9(1):e78644, 2014. 
[36] J. C. Marioni, C. E. Mason, S. M. Mane, M. Stephens, and Y. Gilad. Rna-seq: an assessment of technical reproducibility and comparison with gene expression arrays. Genome Res, 18(9):1509-17, 2008.

[37] M. Gustafsson, M. Hrnquist, and A. Lombardi. Constructing and analyzing a large-scale gene-to-gene regulatory network-lasso-constrained inference and biological validation. IEEE/ACM Trans Comput Biol Bioinform, 2(3):254-61, 2005.

[38] R. Corominas, X. Yang, G. N. Lin, S. Kang, Y. Shen, L. Ghamsari, M. Broly, M. Rodriguez, S. Tam, S. A. Trigg, C. Fan, S. Yi, M. Tasan, I. Lemmens, X. Kuang, N. Zhao, D. Malhotra, J. J. Michaelson, V. Vacic, M. A. Calderwood, F. P. Roth, J. Tavernier, S. Horvath, K. Salehi-Ashtiani, D. Korkin, J. Sebat, D. E. Hill, T. Hao, M. Vidal, and L. M. Iakoucheva. Protein interaction network of alternatively spliced isoforms from brain links genetic risk factors for autism. Nat Commun, 5:3650, 2014.

[39] S. Chun, A. Casparino, N. A. Patsopoulos, D. C. Croteau-Chonka, B. A. Raby, P. L. De Jager, S. R. Sunyaev, and C. Cotsapas. Limited statistical evidence for shared genetic effects of eqtls and autoimmunedisease-associated loci in three major immune-cell types. Nat Genet, 49(4):600-605, 2017.

[40] D. Marbach, D. Lamparter, G. Quon, M. Kellis, Z. Kutalik, and S. Bergmann. Tissue-specific regulatory circuits reveal variable modular perturbations across complex diseases. Nat Methods, 13(4):366-70, 2016.

[41] R. Barshir, O. Shwartz, I. Y. Smoly, and E. Yeger-Lotem. Comparative analysis of human tissue interactomes reveals factors leading to tissue-specific manifestation of hereditary diseases. PLoS Comput Biol, 10(6):e1003632, 2014.

[42] J. Gutierrez-Achury, R. Coutinho de Almeida, and C. Wijmenga. Shared genetics in coeliac disease and other immune-mediated diseases. J Intern Med, 269(6):591-603, 2011.

[43] M. Gustafsson, D. R. Gawel, L. Alfredsson, S. Baranzini, J. Bjrkander, R. Blomgran, S. Hellberg, D. Eklund, J. Ernerudh, I. Kockum, 
A. Konstantinell, R. Lahesmaa, A. Lentini, H. R. Liljenstrm, L. Mattson, A. Matussek, J. Mellergrd, M. Mendez, T. Olsson, M. A. Pujana, O. Rasool, J. Serra-Musach, M. Stenmarker, S. Tripathi, M. Viitala, H. Wang, H. Zhang, C. E. Nestor, and M. Benson. A validated gene regulatory network and gwas identifies early regulators of $t$ cellassociated diseases. Sci Transl Med, 7(313):313ra178, 2015.

[44] K. K. Farh, A. Marson, J. Zhu, M. Kleinewietfeld, W. J. Housley, S. Beik, N. Shoresh, H. Whitton, R. J. Ryan, A. A. Shishkin, M. Hatan, M. J. Carrasco-Alfonso, D. Mayer, C. J. Luckey, N. A. Patsopoulos, P. L. De Jager, V. K. Kuchroo, C. B. Epstein, M. J. Daly, D. A. Hafler, and B. E. Bernstein. Genetic and epigenetic fine mapping of causal autoimmune disease variants. Nature, 518(7539):33743, 2015 .

[45] C. E. Nestor, A. Lentini, C. Hgg Nilsson, D. R. Gawel, M. Gustafsson, L. Mattson, H. Wang, O. Rundquist, R. R. Meehan, B. Klocke, M. Seifert, S. M. Hauck, H. Laumen, H. Zhang, and M. Benson. 5hydroxymethylcytosine remodeling precedes lineage specification during differentiation of human cd4(+) t cells. Cell Rep, 16(2):559-570, 2016.

[46] R. D. Hawkins, A. Larjo, S. K. Tripathi, U. Wagner, Y. Luu, T. Lonnberg, S. K. Raghav, L. K. Lee, R. Lund, B. Ren, H. Lahdesmaki, and R. Lahesmaa. Global chromatin state analysis reveals lineage-specific enhancers during the initiation of human $t$ helper 1 and t helper 2 cell polarization. Immunity, 38(6):1271-84, 2013.

[47] M. Gustafsson, M. Edstrm, D. Gawel, C. E. Nestor, H. Wang, H. Zhang, F. Barrens, J. Tojo, I. Kockum, T. Olsson, J. SerraMusach, N. Bonifaci, M. A. Pujana, J. Ernerudh, and M. Benson. Integrated genomic and prospective clinical studies show the importance of modular pleiotropy for disease susceptibility, diagnosis and treatment. Genome Med, 6(2):17, 2014.

[48] L. Jostins, S. Ripke, R. K. Weersma, R. H. Duerr, D. P. McGovern, K. Y. Hui, J. C. Lee, L. P. Schumm, Y. Sharma, C. A. Anderson, J. Essers, M. Mitrovic, K. Ning, I. Cleynen, E. Theatre, S. L. Spain, S. Raychaudhuri, P. Goyette, Z. Wei, C. Abraham, J. P. Achkar, T. Ahmad, L. Amininejad, A. N. Ananthakrishnan, V. Andersen, 
J. M. Andrews, L. Baidoo, T. Balschun, P. A. Bampton, A. Bitton, G. Boucher, S. Brand, C. Bning, A. Cohain, S. Cichon, M. D'Amato, D. De Jong, K. L. Devaney, M. Dubinsky, C. Edwards, D. Ellinghaus, L. R. Ferguson, D. Franchimont, K. Fransen, R. Gearry, M. Georges, C. Gieger, J. Glas, T. Haritunians, A. Hart, C. Hawkey, M. Hedl, X. Hu, T. H. Karlsen, L. Kupcinskas, S. Kugathasan, A. Latiano, D. Laukens, I. C. Lawrance, C. W. Lees, E. Louis, G. Mahy, J. Mansfield, A. R. Morgan, C. Mowat, W. Newman, O. Palmieri, C. Y. Ponsioen, U. Potocnik, N. J. Prescott, M. Regueiro, J. I. Rotter, R. K. Russell, J. D. Sanderson, M. Sans, J. Satsangi, S. Schreiber, L. A. Simms, J. Sventoraityte, S. R. Targan, K. D. Taylor, M. Tremelling, H. W. Verspaget, M. De Vos, C. Wijmenga, D. C. Wilson, J. Winkelmann, R. J. Xavier, S. Zeissig, B. Zhang, C. K. Zhang, H. Zhao, M. S. Silverberg, V. Annese, H. Hakonarson, S. R. Brant, G. Radford-Smith, C. G. Mathew, J. D. Rioux, E. E. Schadt, et al. Host-microbe interactions have shaped the genetic architecture of inflammatory bowel disease. Nature, 491(7422):119-24, 2012.

[49] J. Z. Liu, S. van Sommeren, H. Huang, S. C. Ng, R. Alberts, A. Takahashi, S. Ripke, J. C. Lee, L. Jostins, T. Shah, S. Abedian, J. H. Cheon, J. Cho, N. E. Dayani, L. Franke, Y. Fuyuno, A. Hart, R. C. Juyal, G. Juyal, W. H. Kim, A. P. Morris, H. Poustchi, W. G. Newman, V. Midha, T. R. Orchard, H. Vahedi, A. Sood, J. Y. Sung, R. Malekzadeh, H. J. Westra, K. Yamazaki, S. K. Yang, J. C. Barrett, B. Z. Alizadeh, M. Parkes, T. Bk, M. J. Daly, M. Kubo, C. A. Anderson, R. K. Weersma, International Multiple Sclerosis Genetics Consortium, and International IBD Genetics Consortium. Association analyses identify 38 susceptibility loci for inflammatory bowel disease and highlight shared genetic risk across populations. Nat Genet, 47(9):979-986, 2015.

[50] D. Wciso-Dziadecka, M. Zbiciak, L. Brzeziska-Wciso, and U. Mazurek. Anticytokine therapy for psoriasis - not only tnf blockers. overview of reports on the effectiveness of therapy with il12/il23 and $t$ and $b$ lymphocyte inhibitors. Postepy Hig Med Dosw (Online), 70(0):11981205, 2016.

[51] E. M. Smigielski, K. Sirotkin, M. Ward, and S. T. Sherry. dbsnp: a database of single nucleotide polymorphisms. Nucleic Acids Res, 
28(1):352-5, 2000.

[52] M. M. McKinney, R. B. Warnecke, and A. D. Kaluzny. Strategic approaches to cancer control research in nci-funded research bases. Cancer Detect Prev, 16(5-6):329-35, 1992.

[53] H. Jeong, B. Tombor, R. Albert, Z. N. Oltvai, and A. L. Barabsi. The large-scale organization of metabolic networks. Nature, 407(6804):651-4, 2000.

[54] M. A. Calderwood, K. Venkatesan, L. Xing, M. R. Chase, A. Vazquez, A. M. Holthaus, A. E. Ewence, N. Li, T. Hirozane-Kishikawa, D. E. Hill, M. Vidal, E. Kieff, and E. Johannsen. Epstein-barr virus and virus human protein interaction maps. Proc Natl Acad Sci USA, 104(18):7606-11, 2007.

[55] Z. Zhao, J. Xia, O. Tastan, I. Singh, M. Kshirsagar, J. Carbonell, and J. Klein-Seetharaman. Virus interactions with human signal transduction pathways. Int J Comput Biol Drug Des, 4(1):83-105, 2011.

[56] S. Bruhn, Y. Fang, F. Barrenas, M. Gustafsson, H. Zhang, A. Konstantinell, A. Kronke, B. Sonnichsen, A. Bresnick, N. Dulyaninova, H. Wang, Y. Zhao, J. Klingelhofer, N. Ambartsumian, M. K. Beck, C. Nestor, E. Bona, Z. Xiang, and M. Benson. A generally applicable translational strategy identifies s100a4 as a candidate gene in allergy. Science translational medicine, 6(218):218ra4, 2014.

[57] A. Portela and M. Esteller. Epigenetic modifications and human disease. Nat Biotechnol, 28(10):1057-68, 2010.

[58] C. E. Nestor, F. Barrens, H. Wang, A. Lentini, H. Zhang, S. Bruhn, R. Jrnsten, M. A. Langston, G. Rogers, M. Gustafsson, and M. Benson. Dna methylation changes separate allergic patients from healthy controls and may reflect altered cd4+ t-cell population structure. PLoS Genet, 10(1):e1004059, 2014.

[59] A. Ashouri, V. I. Sayin, J. Van den Eynden, S. X. Singh, T. Papagiannakopoulos, and E. Larsson. Pan-cancer transcriptomic analysis associates long non-coding rnas with key mutational driver events. Nat Commun, 7:13197, 2016. 
[60] R. E. Drury, D. O'Connor, and A. J. Pollard. The clinical application of micrornas in infectious disease. Front Immunol, 8:1182, 2017.

[61] T. M. Witkos, E. Koscianska, and W. J. Krzyzosiak. Practical aspects of microrna target prediction. Curr Mol Med, 11(2):93-109, 2011.

[62] J. Xue, J. Niu, J. Wu, and Z. H. Wu. Micrornas in cancer therapeutic response: Friend and foe. World J Clin Oncol, 5(4):730-43, 2014.

[63] M. Kumar, S. K. Sahu, R. Kumar, A. Subuddhi, R. K. Maji, K. Jana, P. Gupta, J. Raffetseder, M. Lerm, Z. Ghosh, G. van Loo, R. Beyaert, U. D. Gupta, M. Kundu, and J. Basu. Microrna let-7 modulates the immune response to mycobacterium tuberculosis infection via control of a20, an inhibitor of the nf-b pathway. Cell Host Microbe, 17(3):345$56,2015$.

[64] Y. Bi, G. Liu, and R. Yang. Micrornas: novel regulators during the immune response. J Cell Physiol, 218(3):467-72, 2009.

[65] J. Liu, C. P. Wu, B. F. Lu, and J. T. Jiang. Mechanism of t cell regulation by micrornas. Cancer Biol Med, 10(3):131-7, 2013.

[66] S. Esmailzadeh, B. Mansoori, A. Mohammadi, and B. Baradaran. Regulatory roles of micro-rnas in t cell autoimmunity. Immunol Invest, 46(8):864-879, 2017.

[67] Y. Zhao, X. Shen, T. Tang, and C. I. Wu. Weak regulation of many targets is cumulatively powerful-an evolutionary perspective on microrna functionality. Mol Biol Evol, 34(12):3041-3046, 2017.

[68] A. Krek, D. Grn, M. N. Poy, R. Wolf, L. Rosenberg, E. J. Epstein, P. MacMenamin, I. da Piedade, K. C. Gunsalus, M. Stoffel, and N. Rajewsky. Combinatorial microrna target predictions. Nat Genet, $37(5): 495-500,2005$.

[69] M. J. Li, P. Wang, X. Liu, E. L. Lim, Z. Wang, M. Yeager, M. P. Wong, P. C. Sham, S. J. Chanock, and J. Wang. Gwasdb: a database for human genetic variants identified by genome-wide association studies. Nucleic Acids Res, 40(Database issue):D1047-54, 2012.

[70] G. R. Abecasis, A. Auton, L. D. Brooks, M. A. DePristo, R. M. Durbin, R. E. Handsaker, H. M. Kang, G. T. Marth, G. A. McVean, 
and 1000 Genomes Project Consortium. An integrated map of genetic variation from 1,092 human genomes. Nature, 491(7422):56-65, 2012.

[71] M. Arnold, J. Raffler, A. Pfeufer, K. Suhre, and G. Kastenmller. Snipa: an interactive, genetic variant-centered annotation browser. Bioinformatics, 31(8):1334-6, 2015.

[72] M. Kanehisa. Molecular network analysis of diseases and drugs in kegg. Methods Mol Biol, 939:263-75, 2013.

[73] Ingenuity pathway analysis; ingenuity ${ }^{\circledR}$ systems. http://www. ingenuity.com/.

[74] M. Ashburner, C. A. Ball, J. A. Blake, D. Botstein, H. Butler, J. M. Cherry, A. P. Davis, K. Dolinski, S. S. Dwight, J. T. Eppig, M. A. Harris, D. P. Hill, L. Issel-Tarver, A. Kasarskis, S. Lewis, J. C. Matese, J. E. Richardson, M. Ringwald, G. M. Rubin, and G. Sherlock. Gene ontology: tool for the unification of biology. the gene ontology consortium. Nat Genet, 25(1):25-9, 2000.

[75] Mammalian phenotype database. ftp.informatics.jax.org/pub/ reports/index.html.

[76] A. Franceschini, D. Szklarczyk, S. Frankild, M. Kuhn, M. Simonovic, A. Roth, J. Lin, P. Minguez, P. Bork, C. von Mering, and L. J. Jensen. String v9.1: protein-protein interaction networks, with increased coverage and integration. Nucleic Acids Res, 41(Database issue):D80815,2013

[77] W. E. Johnson, C. Li, and A. Rabinovic. Adjusting batch effects in microarray expression data using empirical bayes methods. Biostatistics, 8(1):118-27, 2007.

[78] A. Conesa, M. J. Nueda, A. Ferrer, and M. Taln. masigpro: a method to identify significantly differential expression profiles in time-course microarray experiments. Bioinformatics, 22(9):1096-102, 2006.

[79] T. A. Knijnenburg, L. F. Wessels, M. J. Reinders, and I. Shmulevich. Fewer permutations, more accurate p-values. Bioinformatics, 25(12):i161-8, 2009. 
[80] M. Milacic, R. Haw, K. Rothfels, G. Wu, D. Croft, H. Hermjakob, P. D'Eustachio, and L. Stein. Annotating cancer variants and anticancer therapeutics in reactome. Cancers (Basel), 4(4):1180-211, 2012 .

[81] D. Szklarczyk, A. Franceschini, M. Kuhn, M. Simonovic, A. Roth, P. Minguez, T. Doerks, M. Stark, J. Muller, P. Bork, L. J. Jensen, and C. von Mering. The string database in 2011: functional interaction networks of proteins, globally integrated and scored. Nucleic Acids Res, 39(Database issue):D561-8, 2011.

[82] Samuel A. Stouffer, Edward A. Suchman, Leland C. DeVinney, Shirley A. Star, and Robin M. Williams Jr. Studies in social psychology in world war ii: The american soldier.adjustment during army life. Princeton University Press, 1, 1949.

[83] S. Peri, J. D. Navarro, T. Z. Kristiansen, R. Amanchy, V. Surendranath, B. Muthusamy, T. K. Gandhi, K. N. Chandrika, N. Deshpande, S. Suresh, B. P. Rashmi, K. Shanker, N. Padma, V. Niranjan, H. C. Harsha, N. Talreja, B. M. Vrushabendra, M. A. Ramya, A. J. Yatish, M. Joy, H. N. Shivashankar, M. P. Kavitha, M. Menezes, D. R. Choudhury, N. Ghosh, R. Saravana, S. Chandran, S. Mohan, C. K. Jonnalagadda, C. K. Prasad, C. Kumar-Sinha, K. S. Deshpande, and A. Pandey. Human protein reference database as a discovery resource for proteomics. Nucleic Acids Res, 32(Database issue):D497$501,2004$.

[84] H. Yu, L. Tardivo, S. Tam, E. Weiner, F. Gebreab, C. Fan, N. Svrzikapa, T. Hirozane-Kishikawa, E. Rietman, X. Yang, J. Sahalie, K. Salehi-Ashtiani, T. Hao, M. E. Cusick, D. E. Hill, F. P. Roth, P. Braun, and M. Vidal. Next-generation sequencing to generate interactome datasets. Nat Methods, 8(6):478-80, 2011.

[85] Ccsb interactome database. http://interactome.dfci.harvard. edu/.

[86] A. Kanhere, A. Hertweck, U. Bhatia, M. R. Gkmen, E. Perucha, I. Jackson, G. M. Lord, and R. G. Jenner. T-bet and gata3 orchestrate th1 and th2 differentiation through lineage-specific targeting of distal regulatory elements. Nat Commun, 3:1268, 2012. 
[87] H. M. Zhang, H. Chen, W. Liu, H. Liu, J. Gong, H. Wang, and A. Y. Guo. Animaltfdb: a comprehensive animal transcription factor database. Nucleic Acids Res, 40(Database issue):D144-9, 2012.

[88] J. Ernst, H. L. Plasterer, I. Simon, and Z. Bar-Joseph. Integrating multiple evidence sources to predict transcription factor binding in the human genome. Genome Res, 20(4):526-36, 2010.

[89] J. Friedman, T. Hastie, and R. Tibshirani. Regularization paths for generalized linear models via coordinate descent. J Stat Softw, $33(1): 1-22,2010$.

[90] B. Langmead and S. L. Salzberg. Fast gapped-read alignment with bowtie 2. Nat Methods, 9(4):357-9, 2012.

[91] Y. Zhang, T. Liu, C. A. Meyer, J. Eeckhoute, D. S. Johnson, B. E. Bernstein, C. Nusbaum, R. M. Myers, M. Brown, W. Li, and X. S. Liu. Model-based analysis of chip-seq (macs). Genome Biol, 9(9):R137, 2008 .

[92] A. R. Quinlan and I. M. Hall. Bedtools: a flexible suite of utilities for comparing genomic features. Bioinformatics, 26(6):841-2, 2010.

[93] T. H. Chang, H. Y. Huang, J. B. Hsu, S. L. Weng, J. T. Horng, and H. D. Huang. An enhanced computational platform for investigating the roles of regulatory rna and for identifying functional rna motifs. BMC Bioinformatics, 14 Suppl 2:S4, 2013.

[94] Geuvadis genetic european variation in health and disease, a european medical sequencing consortium. http://www.geuvadis.org/ web/geuvadis.

[95] J. C. Corvol, D. Pelletier, R. G. Henry, S. J. Caillier, J. Wang, D. Pappas, S. Casazza, D. T. Okuda, S. L. Hauser, J. R. Oksenberg, and S. E. Baranzini. Abrogation of t cell quiescence characterizes patients at high risk for multiple sclerosis after the initial neurological event. Proc Natl Acad Sci U S A, 105(33):11839-44, 2008.

[96] S. Sawcer, G. Hellenthal, M. Pirinen, C. C. Spencer, N. A. Patsopoulos, L. Moutsianas, A. Dilthey, Z. Su, C. Freeman, S. E. Hunt, S. Edkins, E. Gray, D. R. Booth, S. C. Potter, A. Goris, G. Band, A. B. 
Oturai, A. Strange, J. Saarela, C. Bellenguez, B. Fontaine, M. Gillman, B. Hemmer, R. Gwilliam, F. Zipp, A. Jayakumar, R. Martin, S. Leslie, S. Hawkins, E. Giannoulatou, S. D'alfonso, H. Blackburn, F. Martinelli Boneschi, J. Liddle, H. F. Harbo, M. L. Perez, A. Spurkland, M. J. Waller, M. P. Mycko, M. Ricketts, M. Comabella, N. Hammond, I. Kockum, O. T. McCann, M. Ban, P. Whittaker, A. Kemppinen, P. Weston, C. Hawkins, S. Widaa, J. Zajicek, S. Dronov, N. Robertson, S. J. Bumpstead, L. F. Barcellos, R. Ravindrarajah, R. Abraham, L. Alfredsson, K. Ardlie, C. Aubin, A. Baker, K. Baker, S. E. Baranzini, L. Bergamaschi, R. Bergamaschi, A. Bernstein, A. Berthele, M. Boggild, J. P. Bradfield, D. Brassat, S. A. Broadley, D. Buck, H. Butzkueven, R. Capra, W. M. Carroll, P. Cavalla, E. G. Celius, S. Cepok, R. Chiavacci, F. Clerget-Darpoux, K. Clysters, G. Comi, M. Cossburn, I. Cournu-Rebeix, M. B. Cox, W. Cozen, B. A. Cree, A. H. Cross, D. Cusi, M. J. Daly, E. Davis, P. I. de Bakker, M. Debouverie, M. B. D'hooghe, K. Dixon, R. Dobosi, B. Dubois, D. Ellinghaus, I. Elovaara, F. Esposito, et al. Genetic risk and a primary role for cell-mediated immune mechanisms in multiple sclerosis. Nature, 476(7359):214-9, 2011.

[97] A. P. Boyle, E. L. Hong, M. Hariharan, Y. Cheng, M. A. Schaub, M. Kasowski, K. J. Karczewski, J. Park, B. C. Hitz, S. Weng, J. M. Cherry, and M. Snyder. Annotation of functional variation in personal genomes using regulomedb. Genome Res, 22(9):1790-7, 2012.

[98] A. H. Beecham, N. A. Patsopoulos, D. K. Xifara, M. F. Davis, A. Kemppinen, C. Cotsapas, T. S. Shah, C. Spencer, D. Booth, A. Goris, A. Oturai, J. Saarela, B. Fontaine, B. Hemmer, C. Martin, F. Zipp, S. D'Alfonso, F. Martinelli-Boneschi, B. Taylor, H. F. Harbo, I. Kockum, J. Hillert, T. Olsson, M. Ban, J. R. Oksenberg, R. Hintzen, L. F. Barcellos, C. Agliardi, L. Alfredsson, M. Alizadeh, C. Anderson, R. Andrews, H. B. Sndergaard, A. Baker, G. Band, S. E. Baranzini, N. Barizzone, J. Barrett, C. Bellenguez, L. Bergamaschi, L. Bernardinelli, A. Berthele, V. Biberacher, T. M. Binder, H. Blackburn, I. L. Bomfim, P. Brambilla, S. Broadley, B. Brochet, L. Brundin, D. Buck, H. Butzkueven, S. J. Caillier, W. Camu, W. Carpentier, P. Cavalla, E. G. Celius, I. Coman, G. Comi, L. Corrado, L. Cosemans, I. CournuRebeix, B. A. Cree, D. Cusi, V. Damotte, G. Defer, S. R. Delgado, P. Deloukas, A. di Sapio, A. T. Dilthey, P. Donnelly, B. Dubois, 
M. Duddy, S. Edkins, I. Elovaara, F. Esposito, N. Evangelou, B. Fiddes, J. Field, A. Franke, C. Freeman, I. Y. Frohlich, D. Galimberti, C. Gieger, P. A. Gourraud, C. Graetz, A. Graham, V. Grummel, C. Guaschino, A. Hadjixenofontos, H. Hakonarson, C. Halfpenny, G. Hall, P. Hall, A. Hamsten, J. Harley, T. Harrower, C. Hawkins, G. Hellenthal, C. Hillier, et al. Analysis of immune-related loci identifies 48 new susceptibility variants for multiple sclerosis. Nat Genet, 45(11):1353-60, 2013.

[99] D. M. Garcia, D. Baek, C. Shin, G. W. Bell, A. Grimson, and D. P. Bartel. Weak seed-pairing stability and high target-site abundance decrease the proficiency of lsy-6 and other micrornas. Nat Struct Mol Biol, 18(10):1139-46, 2011.

[100] D. Betel, M. Wilson, A. Gabow, D. S. Marks, and C. Sander. The microrna.org resource: targets and expression. Nucleic Acids Res, 36(Database issue):D149-53, 2008.

[101] Y. Li, C. Liang, K. C. Wong, J. Luo, and Z. Zhang. Mirsynergy: detecting synergistic mirna regulatory modules by overlapping neighbourhood expansion. Bioinformatics, 30(18):2627-35, 2014.

[102] O. Martnez and M. H. Reyes-Valds. Defining diversity, specialization, and gene specificity in transcriptomes through information theory. Proc Natl Acad Sci US A, 105(28):9709-14, 2008.

[103] J. MacArthur, E. Bowler, M. Cerezo, L. Gil, P. Hall, E. Hastings, H. Junkins, A. McMahon, A. Milano, J. Morales, Z. M. Pendlington, D. Welter, T. Burdett, L. Hindorff, P. Flicek, F. Cunningham, and H. Parkinson. The new nhgri-ebi catalog of published genome-wide association studies (gwas catalog). Nucleic Acids Res, 45(D1):D896D901, 2017.

[104] J. X. Hu, C. E. Thomas, and S. Brunak. Network biology concepts in complex disease comorbidities. Nat Rev Genet, 17(10):615-29, 2016.

[105] C. S. Greene, A. Krishnan, A. K. Wong, E. Ricciotti, R. A. Zelaya, D. S. Himmelstein, R. Zhang, B. M. Hartmann, E. Zaslavsky, S. C. Sealfon, D. I. Chasman, G. A. FitzGerald, K. Dolinski, T. Grosser, and O. G. Troyanskaya. Understanding multicellular function and 
disease with human tissue-specific networks. Nat Genet, 47(6):569$76,2015$.

[106] J. de Jong Gierveld, N. Keating, and J. E. Fast. Determinants of loneliness among older adults in canada. Can J Aging, 34(2):125-36, 2015.

[107] N. Sahni, S. Yi, M. Taipale, J. I. Fuxman Bass, J. CoulombeHuntington, F. Yang, J. Peng, J. Weile, G. I. Karras, Y. Wang, I. A. Kovcs, A. Kamburov, I. Krykbaeva, M. H. Lam, G. Tucker, V. Khurana, A. Sharma, Y. Y. Liu, N. Yachie, Q. Zhong, Y. Shen, A. Palagi, A. San-Miguel, C. Fan, D. Balcha, A. Dricot, D. M. Jordan, J. M. Walsh, A. A. Shah, X. Yang, A. K. Stoyanova, A. Leighton, M. A. Calderwood, Y. Jacob, M. E. Cusick, K. Salehi-Ashtiani, L. J. Whitesell, S. Sunyaev, B. Berger, A. L. Barabsi, B. Charloteaux, D. E. Hill, T. Hao, F. P. Roth, Y. Xia, A. J. M. Walhout, S. Lindquist, and M. Vidal. Widespread macromolecular interaction perturbations in human genetic disorders. Cell, 161(3):647-660, 2015.

[108] E. Pennisi. The biology of genomes. disease risk links to gene regulation. Science, 332(6033):1031, 2011.

[109] F. W. Albert and L. Kruglyak. The role of regulatory variation in complex traits and disease. Nat Rev Genet, 16(4):197-212, 2015.

[110] Y. G. Tak and P. J. Farnham. Making sense of gwas: using epigenomics and genome engineering to understand the functional relevance of snps in non-coding regions of the human genome. Epigenetics Chromatin, 8:57, 2015.

[111] W. H. Clark. Tumour progression and the nature of cancer. $B r J$ Cancer, 64(4):631-44, 1991.

[112] E. Sato, S. H. Olson, J. Ahn, B. Bundy, H. Nishikawa, F. Qian, A. A. Jungbluth, D. Frosina, S. Gnjatic, C. Ambrosone, J. Kepner, T. Odunsi, G. Ritter, S. Lele, Y. T. Chen, H. Ohtani, L. J. Old, and K. Odunsi. Intraepithelial cd8+ tumor-infiltrating lymphocytes and a high cd $8+/$ regulatory t cell ratio are associated with favorable prognosis in ovarian cancer. Proc Natl Acad Sci U S A, 102(51):18538-43, 2005. 
[113] A. K. Bryant, R. Mudgway, M. P. Huynh-Le, D. R. Simpson, L. K. Mell, S. Gupta, A. B. Sharabi, and J. D. Murphy. Effect of cd4 count on treatment toxicity and tumor recurrence in human immunodeficiency virus-positive patients with anal cancer. Int $J$ Radiat Oncol Biol Phys, 2017.

[114] P. Sharma, Y. Shen, S. Wen, S. Yamada, A. A. Jungbluth, S. Gnjatic, D. F. Bajorin, V. E. Reuter, H. Herr, L. J. Old, and E. Sato. Cd8 tumor-infiltrating lymphocytes are predictive of survival in muscle-invasive urothelial carcinoma. Proc Natl Acad Sci USA, 104(10):3967-72, 2007.

[115] B. Shang, Y. Liu, and S. J. Jiang. Prognostic value of tumorinfiltrating foxp3+ regulatory t cells in cancers: a systematic review and meta-analysis. Sci Rep, 5:15179, 2015.

[116] O. Nakano, M. Sato, Y. Naito, K. Suzuki, S. Orikasa, M. Aizawa, Y. Suzuki, I. Shintaku, H. Nagura, and H. Ohtani. Proliferative activity of intratumoral cd $8(+)$ t-lymphocytes as a prognostic factor in human renal cell carcinoma: clinicopathologic demonstration of antitumor immunity. Cancer Res, 61(13):5132-6, 2001.

[117] S. Navlakha, X. He, C. Faloutsos, and Z. Bar-Joseph. Topological properties of robust biological and computational networks. $J R S o c$ Interface, 11(96):20140283, 2014.

[118] R. D. Leclerc. Survival of the sparsest: robust gene networks are parsimonious. Mol Syst Biol, 4:213, 2008.

[119] K. Venkatesan, J. F. Rual, A. Vazquez, U. Stelzl, I. Lemmens, T. Hirozane-Kishikawa, T. Hao, M. Zenkner, X. Xin, K. I. Goh, M. A. Yildirim, N. Simonis, K. Heinzmann, F. Gebreab, J. M. Sahalie, S. Cevik, C. Simon, A. S. de Smet, E. Dann, A. Smolyar, A. Vinayagam, H. Yu, D. Szeto, H. Borick, A. Dricot, N. Klitgord, R. R. Murray, C. Lin, M. Lalowski, J. Timm, K. Rau, C. Boone, P. Braun, M. E. Cusick, F. P. Roth, D. E. Hill, J. Tavernier, E. E. Wanker, A. L. Barabsi, and M. Vidal. An empirical framework for binary interactome mapping. Nat Methods, 6(1):83-90, 2009.

[120] L. Li, D. J. Ruau, C. J. Patel, S. C. Weber, R. Chen, N. P. Tatonetti, J. T. Dudley, and A. J. Butte. Disease risk factors identified through 
shared genetic architecture and electronic medical records. Sci Transl Med, 6(234):234ra57, 2014.

[121] C. T. Fakhry, P. Choudhary, A. Gutteridge, B. Sidders, P. Chen, D. Ziemek, and K. Zarringhalam. Interpreting transcriptional changes using causal graphs: new methods and their practical utility on public networks. BMC Bioinformatics, 17(1):318, 2016.

[122] J. C. Chen, M. J. Alvarez, F. Talos, H. Dhruv, G. E. Rieckhof, A. Iyer, K. L. Diefes, K. Aldape, M. Berens, M. M. Shen, and A. Califano. Identification of causal genetic drivers of human disease through systems-level analysis of regulatory networks. Cell, 159(2):402-14, 2014.

[123] L. Guo, Y. Du, S. Chang, K. Zhang, and J. Wang. rsnpbase: a database for curated regulatory snps. Nucleic Acids Res, 42(Database issue):D1033-9, 2014.

[124] D. Karolchik, A. S. Hinrichs, T. S. Furey, K. M. Roskin, C. W. Sugnet, D. Haussler, and W. J. Kent. The ucsc table browser data retrieval tool. Nucleic Acids Res, 32(Database issue):D493-6, 2004.

[125] A. Vinayagam, T. E. Gibson, H. J. Lee, B. Yilmazel, C. Roesel, Y. Hu, Y. Kwon, A. Sharma, Y. Y. Liu, N. Perrimon, and A. L. Barabsi. Controllability analysis of the directed human protein interaction network identifies disease genes and drug targets. Proc Natl Acad Sci U S A, 113(18):4976-81, 2016.

[126] T. Pawson and R. Linding. Network medicine. FEBS Lett, 582(8):1266-70, 2008.

[127] E. E. Schadt. Molecular networks as sensors and drivers of common human diseases. Nature, 461(7261):218-23, 2009.

[128] V. P. Bulgakov and G. S.h Tsitsiashvili. Bioinformatics analysis of protein interaction networks: statistics, topologies, and meeting the standards of experimental biologists. Biochemistry (Mosc), 78(10):1098$103,2013$.

[129] E. Ballabio, T. Mitchell, M. S. van Kester, S. Taylor, H. M. Dunlop, J. Chi, I. Tosi, M. H. Vermeer, D. Tramonti, N. J. Saunders, J. Boultwood, J. S. Wainscoat, F. Pezzella, S. J. Whittaker, C. P. Tensen, C. S. 
Hatton, and C. H. Lawrie. Microrna expression in sezary syndrome: identification, function, and diagnostic potential. Blood, 116(7):1105$13,2010$.

[130] M. Salvatore, A. Magrelli, and D. Taruscio. The role of micrornas in the biology of rare diseases. Int J Mol Sci, 12(10):6733-42, 2011.

[131] A. Rebane and C. A. Akdis. Micrornas in allergy and asthma. Curr Allergy Asthma Rep, 14(4):424, 2014.

[132] V. Fulci, G. Scappucci, G. D. Sebastiani, C. Giannitti, D. Franceschini, F. Meloni, T. Colombo, F. Citarella, V. Barnaba, G. Minisola, M. Galeazzi, and G. Macino. mir-223 is overexpressed in tlymphocytes of patients affected by rheumatoid arthritis. Hum Immunol, 71(2):206-11, 2010.

[133] J. Ingwersen, T. Menge, B. Wingerath, D. Kaya, J. Graf, T. Prozorovski, A. Keller, C. Backes, M. Beier, M. Scheffler, T. Dehmel, B. C. Kieseier, H. P. Hartung, P. Kry, and O. Aktas. Natalizumab restores aberrant mirna expression profile in multiple sclerosis and reveals a critical role for mir-20b. Ann Clin Transl Neurol, 2(1):43-55, 2015 .

[134] G. Nogales-Gadea, A. Ramos-Fransi, X. Surez-Calvet, M. Navas, R. Rojas-Garca, J. L. Mosquera, J. Daz-Manera, L. Querol, E. Gallardo, and I. Illa. Analysis of serum mirna profiles of myasthenia gravis patients. PLoS One, 9(3):e91927, 2014.

[135] L. Chen, M. H. L, D. Zhang, N. B. Hao, Y. H. Fan, Y. Y. Wu, S. M. Wang, R. Xie, D. C. Fang, H. Zhang, C. J. Hu, and S. M. Yang. mir1207-5p and mir-1266 suppress gastric cancer growth and invasion by targeting telomerase reverse transcriptase. Cell Death Dis, 5:e1034, 2014.

[136] R. Hamam, A. M. Ali, K. A. Alsaleh, M. Kassem, M. Alfayez, A. Aldahmash, and N. M. Alajez. microrna expression profiling on individual breast cancer patients identifies novel panel of circulating microrna for early detection. Sci Rep, 6:25997, 2016.

[137] S. Vasudevan, Y. Tong, and J. A. Steitz. Switching from repression to activation: micrornas can up-regulate translation. Science, 318(5858):1931-4, 2007. 
[138] R. F. Place, L. C. Li, D. Pookot, E. J. Noonan, and R. Dahiya. Microrna-373 induces expression of genes with complementary promoter sequences. Proc Natl Acad Sci U S A, 105(5):1608-13, 2008.

[139] M. Alexander, R. Hu, M. C. Runtsch, D. A. Kagele, T. L. Mosbruger, T. Tolmachova, M. C. Seabra, J. L. Round, D. M. Ward, and R. M. O'Connell. Exosome-delivered micrornas modulate the inflammatory response to endotoxin. Nat Commun, 6:7321, 2015.

[140] E. Bell and M. A. Taylor. Functional roles for exosomal micrornas in the tumour microenvironment. Comput Struct Biotechnol J, 15:8-13, 2017.

[141] M. Mittelbrunn, C. Gutirrez-Vzquez, C. Villarroya-Beltri, S. Gonzlez, F. Snchez-Cabo, M. Gonzlez, A. Bernad, and F. Snchez-Madrid. Unidirectional transfer of microrna-loaded exosomes from $\mathrm{t}$ cells to antigen-presenting cells. Nat Commun, 2:282, 2011.

[142] I. S. Okoye, S. M. Coomes, V. S. Pelly, S. Czieso, V. Papayannopoulos, T. Tolmachova, M. C. Seabra, and M. S. Wilson. Micrornacontaining t-regulatory-cell-derived exosomes suppress pathogenic t helper 1 cells. Immunity, 41(1):89-103, 2014.

[143] M. All, V. Buggiano, J. P. Fededa, E. Petrillo, I. Schor, M. de la Mata, E. Agirre, M. Plass, E. Eyras, S. A. Elela, R. Klinck, B. Chabot, and A. R. Kornblihtt. Control of alternative splicing through sirna-mediated transcriptional gene silencing. Nat Struct Mol Biol, 16(7):717-24, 2009.

[144] M. Ameyar-Zazoua, C. Rachez, M. Souidi, P. Robin, L. Fritsch, R. Young, N. Morozova, R. Fenouil, N. Descostes, J. C. Andrau, J. Mathieu, A. Hamiche, S. Ait-Si-Ali, C. Muchardt, E. Batsch, and A. Harel-Bellan. Argonaute proteins couple chromatin silencing to alternative splicing. Nat Struct Mol Biol, 19(10):998-1004, 2012.

[145] J. Liu, J. Hu, and D. R. Corey. Expanding the action of duplex rnas into the nucleus: redirecting alternative splicing. Nucleic Acids Res, 40(3):1240-50, 2012.

[146] B. A. Maron, Y. Y. Zhang, K. White, S. Y. Chan, D. E. Handy, C. E. Mahoney, J. Loscalzo, and J. A. Leopold. Aldosterone inactivates the 
endothelin-b receptor via a cysteinyl thiol redox switch to decrease pulmonary endothelial nitric oxide levels and modulate pulmonary arterial hypertension. Circulation, 126(8):963-74, 2012.

[147] A. Lee, J. G. Oh, P. A. Gorski, R. J. Hajjar, and C. Kho. Posttranslational modifications in heart failure: Small changes, big impact. Heart Lung Circ, 25(4):319-24, 2016.

[148] S. Muthusamy, A. M. DeMartino, L. J. Watson, K. R. Brittian, A. Zafir, S. Dassanayaka, K. U. Hong, and S. P. Jones. Microrna-539 is up-regulated in failing heart, and suppresses o-glcnacase expression. J Biol Chem, 289(43):29665-76, 2014.

[149] E. Guney, J. Menche, M. Vidal, and A. L. Barbasi. Network-based in silico drug efficacy screening. Nat Commun, 7:10331, 2016. 


\section{Papers}

The papers associated with this thesis have been removed for copyright reasons. For more details about these see:

http://urn.kb.se/resolve?urn=urn:nbn:se:liu:diva-147047 